\title{
Using a climate-to-fishery model to simulate the influence of the 1976-1977 regime shift on anchovy and sardine in the California Current System
}

\author{
Haruka Nishikawa ${ }^{1 *}$ (D, Enrique N. Curchitser ${ }^{2}$, Jerome Fiechter ${ }^{3}$, Kenneth A. Rose ${ }^{4}$ and Kate Hedstrom ${ }^{5}$
}

\begin{abstract}
The influence of the well-known 1976-1977 regime shift on the Northern anchovy (Engraulis mordax) and the Pacific sardine (Sardinops caeruleus) populations in the California Current System (CCS) is investigated using a climateto-fishery model. This model consists of four coupled submodels (regional ocean circulation model; Eulerian nutrient-phytoplankton-zooplankton-detritus model; individual-based full life cycle anchovy and sardine model; agent-based fishery model). Analysis of a historical simulation (1958-1990) showed that survival fraction of age-0 anchovy was lower just after 1977, while survival fraction of age-0 sardine was relatively unaffected by the regime shift. The age-0 survival of both species was influenced by the growth in the larval stage. Simulated zooplankton densities in the historical simulation shifted from high to low in 1976-1977 in the CCS, with the shift being most drastic in winter in the coastal area. The model also shows that anchovy larvae feed extensively from winter to early spring in the coastal area, while sardine larvae were mainly distributed in the offshore area. The differential seasonal and spatial responses of zooplankton in the simulation caused anchovy survival to be more sensitive than sardine to the 1976-1977 regime shift. The model-generated zooplankton shift was a result of reduced phytoplankton production due to lowered nutrient concentrations after 1977 due to the weakening of both the coastal upwelling and mixed layer shoaling, which reduced the vertical nutrient flux from the bottom layer to the surface layer.
\end{abstract}

Keywords: California Current System, Anchovy, Sardine, Individual-based model, Climate-to-fishery model, Regime shift

\section{Introduction}

\section{Background}

Anchovy (Engraulis sp.) and sardine (Sardinops sp.) are important harvested species in four regions of the world: California Current system (CCS), Humboldt Current System, Benguela Current System, and the KuroshioOyashio Current System. Those stocks exhibit a low frequency (decadal) variability and, except for the Humboldt system, out-of-phase-like synchrony (to various degrees) of stock variation between anchovy and sardine (Lluch-Belda et al. 1989; Lluch-Belda et al. 1992;

\footnotetext{
* Correspondence: harukan@jamstec.go.jp

${ }^{1} J a p a n$ Agency for Marine-Earth Science and Technology, 3173-25

Showa-machi, Kanazawa-ku, Yokohama, Kanagawa 236-0001, Japan

Full list of author information is available at the end of the article
}

Schwartzlose et al. 1999). Kawasaki (1983) and LluchBelda et al. (1989) found synchronized stock variation patterns of anchovy and sardine world-wide and suggested that these stock variations are influenced by global-scale climate forcing. Many correlation-based studies suggest that there are many processes linking climate forcing with the resulting variability in fish stocks (e.g., Yatsu et al. 2008), but it is difficult to separate the influences of the various environmental and biological factors and harvest that all often covary together. Our approach here is to use a coupled modeling system and apply the model to sardine and anchovy in the CCS to elucidate the various processes that connect climate forcing to sardine and anchovy stock variation. 
A reliable climate-to-fishery model is capable of demonstrating how certain modes of climate variability can impact fish stocks. The climate-to-fishery model used in this paper was originally implemented for anchovy and sardine in the CCS and, using a 1959 to 2008 historical simulation, was shown to adequately reproduce decadal scale stock variation of Northern anchovy (Engraulis mordax) and the Pacific sardine (Sardinops caeruleus) (Rose et al. 2015). Further analysis of the model output demonstrated the role of environmental variability and prey availability in setting up conditions favorable for the anchovy and sardine populations in the CCS (Fiechter et al. 2015). In the present study, we further investigate an updated historical simulation (using an expanded model grid) by focusing on identifying the environmental factors and life stages that influenced the sardine and anchovy population responses after a notable climate change event, namely the 1976-1977 North Pacific regime shift.

\section{Motivation}

The North Pacific climate exhibited an abrupt change from 1976 to 1977 (Graham 1994; Miller et al. 1994), which was characterized by a decrease in sea surface temperature (SST) in the central Pacific and a rise of SST in the eastern Pacific including the California Current (Venrick et al. 1987; Cayan 1992; Roemmich 1992). This period also coincided with major changes in many North Pacific ecosystems that collectively have become recognized as an ecological regime shift or phase transition (McGowan et al. 2003). Examples of species that were influenced by the regime shift in the CCS include giant kelp (Parnell et al. 2010), zooplankton (Mackas et al. 2001), salmon (Beamish et al. 2000), soles (McFarlane et al., 2000), and marine mammals (Stone et al. 1997).

Considering the different stock variation patterns of anchovy and sardine in the CCS, we speculate that the regime shift should have opposite impacts on their populations. Consequently, some studies imply that the change of ocean environment associated with the 1976-1977 regime shift triggered a species replacement (Benson and Trites 2002; Chavez et al. 2003). Hare and Mantua (2000) reported that survival of age- 0 anchovy on the US west coast decreased after the regime shift. They also describe the decrease of zooplankton abundance. Their suggestion that the regime shift lowered anchovy survival via reduced food availability can be tested using a coupled modeling framework. Fiechter et al. (2015), using the same model as used here, identified periods of enhanced adult anchovy growth associated with increased prey availability in the CCS leading to increased egg production. Anchovy and sardine are both plankton feeders that occur from British Columbia to Baja California and can form mixed schools (Radovitch 1979). If the poor feeding condition caused a low age- 0 survival of anchovy, then we might expect that age- 0 survival of sardine was also low during the same time period. Previous studies, including the model used here, suggested that age-0 survival exerts a significant control on adult sardine abundance via increased egg survival (i.e., reduced development time) during periods of warmer ocean conditions, such as those that occurred following the 1976-1977 regime shift (Fiechter et al. 2015). While sardine catch data in British Columbia did not show the apparent phase transition during the regime shift (McFarlane and Beamish, 1999), Barnes et al. (1992) suggested that age-0 sardine improved in California during the 1970s.

The sardine and anchovy ecological niches overlap to some extent. Due to differences in their spawning timing and locations, the overlap is relatively small in their early life stages. Peak spawning season of anchovy is from January to April and that of sardine is from February to June (Moser et al. 2001). Sardine spawning grounds extend more offshore than anchovy spawning grounds (Hernandez-Vazquez 1994). There are also differences in their feeding ecology. Sardine has finer mesh gill rakers than anchovy and therefore consumes smaller plankton as forage (Van der Lingen et al. 2006).

There are two important upwelling conditions that supply nutrients to the surface layer in the CCS. One is coastal upwelling due to alongshore wind stress (Ekman transport), and another is curl-driven upwelling due to wind stress curl (Ekman pumping) (Rykaczewski and Checkley 2008). While coastal upwelling is typically more intense and leads to primary production dominated by larger phytoplankton types, its effects are limited to the nearshore region. In contrast, weaker curl-driven upwelling extends farther offshore and supports primary production associated with smaller phytoplankton types. Based on species distribution and diet preferences, Rykaczewski and Checkley (2008) hypothesized that sardine survival in the CCS is related to the magnitude of curl-driven upwelling, while anchovy survival is related to the magnitude of coastal upwelling. The idea that anchovy and sardine survival are controlled by the different environmental factors related to differences in their habitat niche might explain the different response of age-0 dynamics to the 1976-1977 regime shift. Our analysis expands on modeling analyses to date (Deyle et al. 2013; Lindegren et al. 2013; Kaplan et al. 2017) by using coupled 3D ecosystem models to examine food availability and fish experiences on detailed spatial and temporal scales that are difficult from field data and spatially aggregated models. In addition, although the fish surveys have been conducted in the CCS for decades, reliable stock size estimates for sardine 
are not available around the regime shift due to the moratorium on fishing along the California coast from 1967 to 1985.

\section{Methods/Experimental}

We used the climate-to-fishery model of Rose et al. (2015) with the only changes being the southward expansion of the model domain to better represent the natural range of the fish populations and increased horizontal and vertical resolution of the grid. Below, we briefly present the four submodels that comprise the climate-fishery model and describe the methods we used to analyze the model output for regime shifts and for estimating coastal and curl-driven upwelling. A complete description of the coupled climate-to-fishery model is given in Rose et al. (2015). An updated simulation of the period from 1958 to 1990 is analyzed here; our focus is on dynamics before and after the 1977 regime shift.

\section{Climate-to-fishery model \\ Regional ocean circulation model}

The ocean circulation model for the CCS is an implementation of the Regional Ocean Modeling System (ROMS; Haidvogel et al. 2008; Shchepetkin and McWilliams 2005) along the west coast of North America. The domain extends in latitude from the Baja California Peninsula $\left(19^{\circ} \mathrm{N}\right)$ to British Columbia $\left(50^{\circ} \mathrm{N}\right)$. The grid extends about $2300 \mathrm{~km}$ alongshore and about $1200 \mathrm{~km}$ offshore. The current domain is expanded from the original domain of Fiechter et al. (2015), which originally extended from 30 to $48^{\circ} \mathrm{N}$, to allow for movement of sardine and anchovy farther south. The current horizontal grid resolution is $7 \mathrm{~km}$, and the vertical resolution is set to 50 non-uniform terrain-following levels. The ROMS model is forced on all open boundaries by weekly averaged fields from the Simple Ocean Data Assimilation (SODA) reanalysis to force the model with realistic transport values and temperature profiles (Carton et al. 2000; Rose et al. 2015). Surface forcing is derived from the datasets for Common Ocean-Ice Reference Experiments (CORE2; Large and Yeager 2008), which consist of 6 hourly winds, air temperature, sea level pressure and specific humidity, and daily short-wave and downwelling long-wave radiation and monthly precipitation.

\section{NPZ model}

The nitrogen concentration-based NPZ food web model NEMURO (Kishi et al. 2007) used in the present study contains 11 compartments, which represent small phytoplankton (PS), large phytoplankton (PL), small zooplankton (ZS), large zooplankton (ZL), predatory zooplankton (ZP), nitrate $\left(\mathrm{NO}_{3}\right)$, ammonium $\left(\mathrm{NH}_{4}\right)$, silicate $\left(\mathrm{Si}(\mathrm{OH})_{4}\right)$, particulate organic nitrogen $(\mathrm{PON})$, biogenic silica (Opal), and dissolved organic nitrogen (DON). NEMURO is coupled to ocean circulation by solving a transport equation in ROMS for each NEMURO component at every time step. The initial and boundary conditions for nitrate and silicic acid are derived from monthly climatological concentrations (World Ocean Atlas 2001, $1^{\circ} \times 1^{\circ}$ horizontal resolution; Conkright and Boyer 2002). This model can reproduce realistic chlorophyll-a, nitrate, and temperature distribution (Rose et al. 2015).

\section{Individual-based fish model}

The individual-based fish model (IBM) is parameterized to represent anchovy and sardine. The IBM tracks individuals in continuous (Lagrangian) space within the ROMS 3D grid. Anchovy and sardine life cycles are defined by the egg, yolk-sac larva, larva, juvenile, and adult life stages. Temperature determines egg and yolk-sac larval development; length determines metamorphosis and maturation. Individuals are aged by 1 year on January 1 . The IBM also includes a migratory predator species (similar to albacore) that imposes dynamically varying predation mortality rates on anchovy and sardine. While the population dynamics of sardine and anchovy are simulated with a full life cycle approach (adults release young who grow up to be adults and release young, etc.), only the movement and consumption of the predator species individuals is simulated. The position of each individual in three-dimensional space is updated hourly and followed both in continuous (longitude, latitude, depth) space and grid cell location.

Growth of larval, juvenile, age-1, and older anchovy and sardine individuals is computed based on bioenergetics and a functional response relationship. The functional response determines the hourly consumption rate and uses zooplankton concentrations interpolated to its location from NEMURO-generated zooplankton concentration in nearby spatial cells. The diet preferences (weighting of different zooplankton groups) vary according to species and life stage.

Four sources of mortality of sardine and anchovy are represented: natural, starvation, predation by albacore, and a fishing fleet. Natural mortality has a constant rate specific to each life stage. Starvation occurs when the fish weight drops below a minimum value allowed for that length. The effects of albacore predation (on both species) and fishing (sardine only) mortality is limited to age-1 and older individuals. Mortality values are derived from Butler et al. (1993) and Lo et al. (1995). Since their estimation of mortality values were based on observation, they estimated the value with a width. We choose the average values that they assumed for simulation, but it is possible that the uncertainty of estimation causes the uncertainty of the simulation results.

Eggs, yolk-sac larvae, and larvae are moved horizontally using a passive transport (particle-tracking). Juvenile and 
adult anchovy and sardine individuals are moved every hour using a three-dimensional behavior (independent of physics) based on a kinesis approach (Humston et al. 2000, 2004; Watkins and Rose 2013). The movement cues are the temperature and prey availability at the individual's present location. A seasonal feeding migration is also imposed on sardine individuals by biasing the kinesis movement poleward in May and equatorward during the September spawning migration. Eggs and yolk-sac larvae were positioned in a vertical layer, while larvae, juveniles, and adults were moved vertically within the water column by first locating them horizontally with kinesis and then moving them to the cell within the water column with the highest prey availability. The simulated sardine egg and larval distributions are consistent with the observation data (Politikos et al. 2018).

Reproduction of mature fish (greater than a specific length on January 1) is represented as an allocation between somatic growth and egg production. Each batch of eggs is kept track of in an individual as the eggs develop or are resorbed; the model is configured to produce realistic numbers of egg per batch and number of batches per year for anchovy and sardine. The timing of batch releases depends mostly on the energy stores of the individual at the beginning of the spawning season (January 1 to May 1 for anchovy and February 1 to July 1 for sardine). A fecundity of batch depends on an individual female weight (Hunter et al. 1985). In the simulation therefore, eggs per individual is related to weight and lagged annual growth rates and weights of younger classes. A previous study investigated the simulation and concluded that the long-term anchovy abundance is associated with age-1 growth via age- 2 egg production (Fiechter et al. 2015).

The IBM uses a version of the super-individual approach (Scheffer et al. 1995), where a fixed number of model individuals are followed, with each model individual worth some number of identical population individuals. Mortality from all sources (except starvation) acts to reduce the worth of each super-individual over time. Upon reaching a maximum age, super-individuals are removed and their place in arrays is available to place new super-individuals to represent the next year's production of eggs. Location, worth (abundance of the individual), weight, growth, diet, and reproduction (if mature) are recorded every first hour of the day for each super-individual.

\section{Agent-based fishery model}

Fishing occurs every day of the year, as long as boats have access to a grid cell where expected net revenue is positive. The daily location choice, and associated daily catch, of individual boats that fish sardine individuals is simulated using a simplified multinomial logit, agent-based approach where boats maximize their expected net revenue for each trip. Details of the agent-based fishery model are written in Rose et al. (2015).

\section{Model outputs}

Model outputs reported here are computed (summed, averaged) taking into account the worth of the super-individuals. For example, total adult biomass is the sum of worth over super-individuals and average length-at-age is a statistically weighted average over individuals using their worth as the weighting factors. The specific calculations for many of the outputs reported here are detailed in Table 6 of Rose et al. (2015) and Additional file 1: Table S1.

\section{Regime shift detection}

A regime shift index (RSI) (Rodionov 2004) is applied to model results to identify significant regime shifts. The basic idea of detecting regime shift is to compare the average values of variables before and after a regime shift. The difference diff, which depends on accuracy of detection and detection length is set.

$$
\operatorname{diff}=t \sqrt{2 \sigma_{l}^{2} / l}
$$

Here, $t$ is the value of $t$ distribution with $2 l-2^{\circ}$ of freedom at the given probability level $p, \sigma_{l}^{2}$ is the average variance for running $l$ year intervals in the time series of variables, and $l$ is the cutoff length of the regimes. We set the significant criterion at the probability level 0.05 by a $t$ test with certain years of the cutoff length. Three, five, seven, and ten years are used in RSI detection for the recruitment, and 10 years are used for other cases. Then, the levels that should be reached in the subsequent $l$ years to qualify for a shift from regime R1 to regime R2 are estimated.

$$
{\overline{x_{R 2}}}^{\prime}=\overline{x_{R 1}} \pm \text { diff }
$$

$\overline{x_{R 1}}$ is the average of variables during regime R1. Finally, RSI for variable $x$ in year $j$ is calculated.

$$
\operatorname{RSI}_{i, j}=\sum_{i=j}^{j+m} \frac{x_{i}^{*}}{l \sigma_{l}}, m=0, \ldots, l-1
$$

When the regime shift is up, $x_{i}^{*}=x_{i}-\overline{x_{R 2}}$ and when the shift is down, $x_{i}^{*}=\overline{x_{R 2}}-x_{i}$. If at any time from $i=j+$ 1 to $i=j+l-1$ the RSI value turns negative, the detection fails. We applied this regime shift detection method to the time series of model-generated stage survivals of anchovy and sardine, and the biological and physical variables (some are inputs and some are outputs) that affect the stage survival (e.g., zooplankton density, wind speed). 
The idea was to detect any responses of model results to the 1976-1977 regime shift.

We also use our computed RSI values to show a spatial and temporal distribution pattern of a regime shift for certain environmental variables (e.g., zooplankton density) for each month. The environmental variables are binned on the horizontal grids from $7 \mathrm{~km} \times 7$ $\mathrm{km}$ to $1^{\circ} \times 1^{\circ}$ and averaged in the upper $30 \mathrm{~m}$ of the water column, which corresponds to the main habitat depth of anchovy and sardine larvae.

When the RSI is detected in the significant levels of $0.05,0.1$, and 0.2 in 1977, we draw the RSI distributions on the map of the model grid. The original RSI always returns a positive value if the regime shift is up or down. In this study, we assign negative value for detected regimes that result in a negative shift.

\section{Upwelling}

Upwelling in the CCS is produced by two different processes: coastal upwelling and curl-driven upwelling (Pickett and Schwing 2006). Here, we estimate the vertical transport associated with both types of upwelling using the results for the historical simulation. Coastal upwelling velocity, $w_{\text {coast }}$, can be calculated given the density of seawater, $\rho_{0}$, alongshore wind stress within 10 $\mathrm{km}$ of the coastline, $\tau_{a}$, and the local Rossby radius of deformation, $R_{d}$ (Smith 1968). $\tau_{a}$ was obtained from interpolated CORE2 data that is used as boundary conditions for ROMS. Based on earlier studies in the region, a Rossby radius of $10 \mathrm{~km}$ is used in the calculation (Pickett and Schwing 2006; Rykaczewski and Checkley 2008).

$$
w_{\text {coast }}=\frac{\tau_{a}}{\rho_{0} f} \cdot \frac{1}{R_{d}}
$$

The curl-driven upwelling velocity, $w$, can be calculated from Smith (1968):

$$
w=\frac{1}{\rho_{0} f} \nabla \times \boldsymbol{\tau}
$$

where $\nabla \times \boldsymbol{\tau}$ is the curl of the derived wind stress vector; $\rho_{0}$ is the density of seawater, and $f$ is the Coriolis parameter. Volumes of the coastal upwelling and curl-driven upwelling for a certain area during a certain period are calculated by these coastal upwelling and curl-driven upwelling velocities.

We divide the main sardine and anchovy habitats from $24^{\circ} \mathrm{N}$ to $40^{\circ} \mathrm{N}$ into a coastal region and an offshore region because observations and previous simulation reported that anchovy larvae have greater affinity for coastal waters than sardine larvae (Hernandez-Vazquez 1994; Rose et al. 2015). The coastal region is defined as nearshore and is dominated by upwelling. The vertical velocity is integrated from $2 \mathrm{~m}$ to $120 \mathrm{~m}$ depth (Song et al. 2011) and averaged in $2^{\circ} \times 2^{\circ}$ grid cells from January to June for each year. We define the region where the averaged vertical velocity from 1967 to 1986 is upward as the predominant upwelling region. Also, we divided larvae based on the center of gravity location of larval stage distribution. When the center of gravity is located inside (outside) the coastal region, the larva is named as "coastal larvae" ("offshore larvae"). To avoid artificial effects from dynamics near the boundaries, we removed the larvae from offshore larvae that are distributed in the grid cells next to the boundary. This is resulted in about $1 \%$ of offshore sardine larvae being removed from analyses.

In the latter half of analysis, we focused on the physical and biological components averaged in the coastal region. Zooplankton, phytoplankton, nutrients, and mixed layer depth (MLD) data used there were from simulation results, and heat flux, wind stress, wind speed, and temperature data were from the model input derived from the CORE2 data. In this study, the MLD was operationally defined as the depth where the temperature is $0.8^{\circ} \mathrm{C}$ lower than the surface (Kara et al. 2000).

\section{Analysis of the mixed layer depth}

The change in the MLD also had an impact on the surface ecosystem dynamics in the historical simulation. In the CCS, the heat flux from the atmosphere to the ocean, the intensity of turbulent wind mixing, and coastal upwelling erode stratification in the upper layer of the water column and deepen the mixed layer (Husby and Nelson 1982). Among these factors, the MLD variation is mainly due to wind (Jeronimo and GomezValdes 2010). We therefore estimated the impact of the wind speed regime shift on the MLD regime shift in the simulation by using a bulk formulation of the entrainment velocity. The entrainment velocity is a measure of the evolution of the mixed layer, and therefore, we use the time integration of the entrainment velocity as a metric for mixed layer development. Qiu and Kelly (1993) provides a bulk model of the entrainment velocity, which contains the effects of wind mixing, absorption of the short-wave radiation, and potential energy changes from the net heat flux. We extracted the effect of wind mixing on the entrainment velocity from their bulk formulation as follows:

$$
W_{e}=m_{0} u_{*}^{3} \cdot \frac{1}{\mathrm{MLD}} \cdot \frac{1}{\Delta T} \cdot \frac{2}{\alpha g}
$$

In Eq. 6, the entrainment velocity $W_{e}(\mathrm{~m} / \mathrm{s})$ is the objective variable. The parameter $m_{0}$ (set to 0.5 ) is the coefficient for the vertical wind mixing, $u *$ is the frictional velocity defined as $u_{*}=\left(\tau / \rho_{0}\right)^{1 / 2}$ for wind stress $\tau$ and sea water density $\rho_{0}\left(=1025 \mathrm{~kg} / \mathrm{m}^{3}\right)$, MLD is the mixed layer 
depth at that time, $\alpha\left(=0.00025{ }^{\circ} \mathrm{C}^{-1}\right)$ is thermal expansion coefficient, $g$ is gravitational acceleration, and $\Delta T$ (set to $1.0^{\circ} \mathrm{C}$, Qiu and Kelly 1993) is the temperature difference between the mixed layer and entrained subsurface water. The entrainment velocity at each time step is then calculated according to Eq. 6. We integrate the estimated entrainment velocities from October to February for each year in order to estimate the evolution of the mixed layer depth due to changes in the winds throughout the season. Then, we compared the average of the mixed layer development by wind for the periods before (1967-1976) and after (1977-1986) the regime shift.

\section{Results}

\section{Comparison between model results and observations}

Simulated long-term increasing trends of age- 1 and older biomass of anchovy and sardine compared favorably to catch data from the Food and Agriculture Organization (Fig. 1). For anchovy, reported catch increased from 1958, with a maximum catch recorded in 1981 (Fig. 1a, gray line with crosses), until catch then sharply decreased after 1983. Simulated age-1 and older biomass of anchovy also increased from 1964 to 1982 and slightly decreased from 1982 to 1984, but then remained fairly constant after 1985 (Fig. 1a, black line with closed circles). Thus, simulated anchovy biomass exhibits a similar increasing trend as catch but levels off rather than sharply drops. Observations show that the El Niño in 1983 had a strongly negative influence on anchovy populations (Fielder 1984), which may be underestimated in the model simulation.

Simulated adult biomass and catch of sardine both show an increasing trend (Fig. 1b). The two drops in catch (1984 and 1989, Fig. 1b, gray line with crosses) are not captured by the model.

In our analysis, we focus on the interannual variability of the survival of the early life stages. Previous studies used empirical data and estimated recruitment rates (age-0 biomass per spawning stock biomass) from 1964 to 1991 for anchovy (Jacobson et al. 1994) and from 1936 to 1964 and from 1987 to 1991 for sardine (Jacobson and MacCall 1995). We compare the normalized recruitment rate from our climate-to-fishery model with these reported estimates. In our calculation of recruitment rate, we used mature adult biomass instead of spawning stock biomass. Anchovy recruitment rate anomalies from previous study were negative from 1964 to late 1960s, positive from 1971 to 1976 and relatively negative after 1977 (Fig. 2a). In the simulation, the recruitment rate anomalies are negative before 1964, positive from 1965 to 1976, and negative after 1977 (Fig. 2b). The regime shift in 1977 is detected with a 7-year cutoff length for the previous study and also detected with a 10-year cutoff length for the current simulation. Although there is a difference between the previous study and the simulation around late 1960s, a regime shift occurred in 1977 after a regime of 7-10 years in both cases. For the sardine recruitment, it is difficult to compare the simulation with previous study, because the overlap of data period is very short. In the previous study, a regime was about 3 years occurred just prior to 1964, but the trend in 1970s was unknown (Fig. 2c). In the historical simulation, a shift was detected in 196 after an approximate 5-year regime period and there is no regime shift in 1977 (Fig. 2d). Mean and standard deviation of anchovy recruitment rate in previous study during 1964-1989 is $2.71 \pm 2.39$. For the historical simulation, mean and standard deviation for the same period is $1.41 \pm 0.29$. Thus, the stock level and amplitude of stock variation was underestimated in the historical simulation. Sardine recruitment shows the same tendency. Mean and standard deviation of sardine recruitment rate in previous study during 1936-1964 and $1987-1991$ is $4.10 \pm 4.03$ compared to $0.75 \pm 0.11$ during 1959-1990 in the simulation. For the sardine, the comparison periods are different. But the sardine stock level
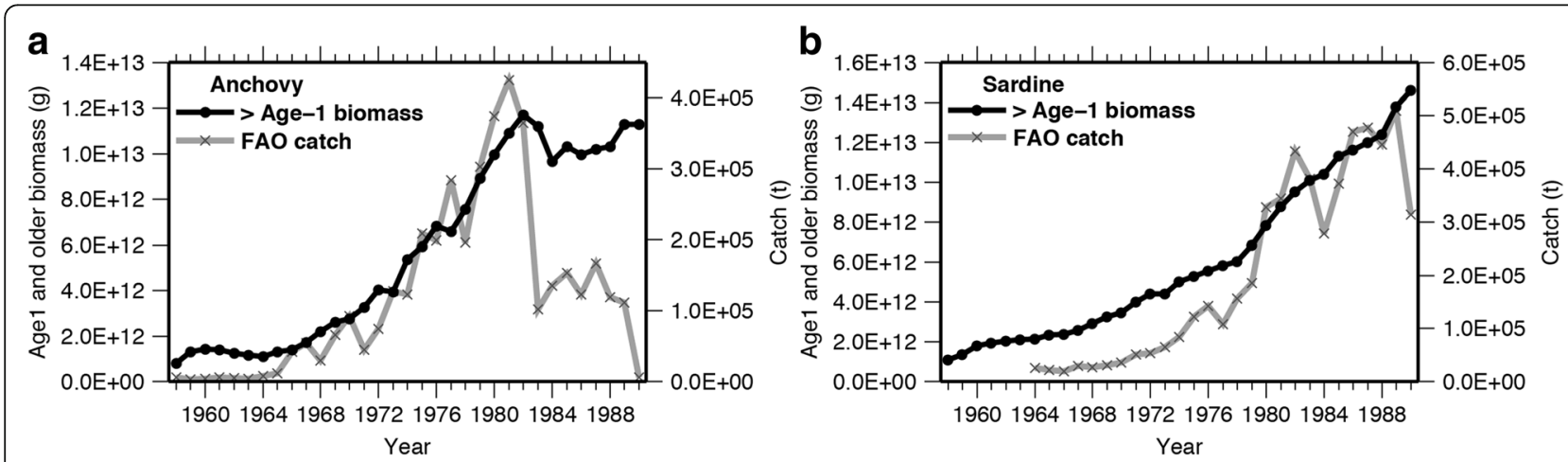

Fig. 1 Comparison between model simulation results and observations for adult population biomass and catch. Model simulated a age-1 and older anchovy biomass and catch from FAO from 1958 to 1990 and $\mathbf{b}$ age-1 and older sardine biomass and catch from FAO from 1964 to 1990. Model simulation data is plotted in black line with close circles and FAO data is plotted in gray line with crossed through 

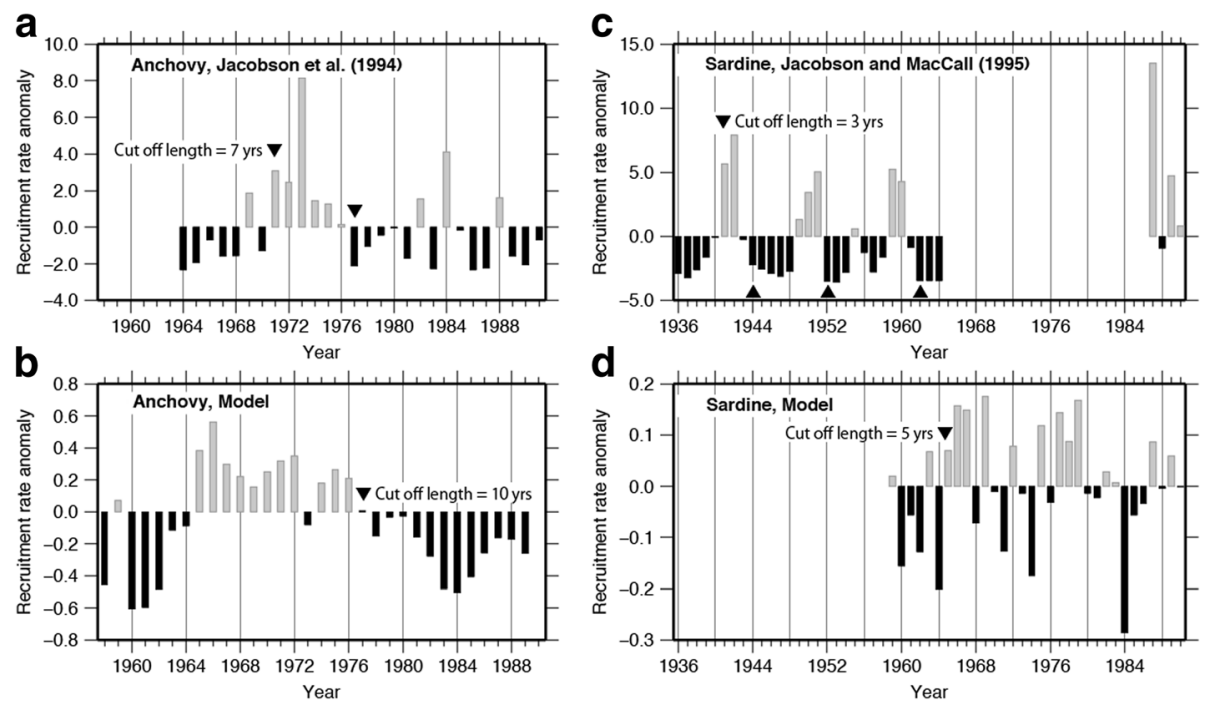

Fig. 2 Comparison of recruitment rate anomaly between model simulation and estimates based on analysis of field data. Time series of anchovy a estimated by Jacobson et al. (1994) from 1964 to 1991, b estimated by the climate-to-fishery model from 1958 to 1990, normalized sardine rate c estimated by Jacobson and MacCall (1995) from 1936 to 1964 and from 1987 to 1991 and d estimated by the climate-to-fishery model from 1958 to 1990. Mean recruitment rate that was used for calculating anomaly is a 2.71, b 1.40, c 4.09, and d 0.75 . Triangles represent years when the regime shift index detected by RSI. Cutoff lengths are $\mathbf{a} 7$ years, $\mathbf{b} 10$ years, $\mathbf{c} 3$ years, and $\mathbf{d} 5$ years

and amplitude of stock variation was also underestimated in the simulation.

We further investigated the variation in recruitment rate by examining the survival of the larval stage. Larval stage dynamics is often a driver of recruitment success (Hjort 1914; Houde 1987; Cushing 1990). In the California Current System, the California Cooperative Oceanic Fisheries Investigations project (CalCOFI) (calcofi.org) is a long-term observation program focused on physical and biological ocean conditions related to larval stage dynamics. We compare larval abundance between the model and the CalCOFI data. Simulated larval abundance is defined by the cumulative number of larvae produced each year. Larvae abundance data from CalCOFI is the integrated counts of larvae per $10 \mathrm{~m}^{2}$ in oblique net tows from January to June for anchovy and from January to August for sardine.

CalCOFI data show that anchovy larvae appeared to increase from the end of 1960 s to the early 1970s, abundance became low in late 1970s until a peak in the mid-1980s, after which larval abundance returned to relatively low levels (Fig. 3a). Larval abundance in the simulation reproduces a similar increasing trend from the end of 1960s to early 1970s and then relatively stable values after that (Fig. 3a). For sardine larvae, the simulated abundance shows a similar long-term increasing trend as the CalCOFI data from the end of the 1960s to the early 1980s, but it does not reproduce the short-term fluctuation in mid-1980s (Fig. 3b).
While simulated and observed recruitment rate of anchovy showed a clear response to the 1977 regime shift (Fig. 2a and b), simulated adult biomass (Fig. 1a) and larval abundance (Fig. 3a) did not. This is because the egg production increases during this time period in the simulation that more than offset the lowered recruitment rates (Fig. 4a). Thus, the regime shift did not have a negative influence on the anchovy biomass itself. The egg production depends on adult female biomass and an individual female weight, which is determined by lagged annual growth rates. If the adult biomass increase led the egg production increase, the age- 0 abundance would increase prior to the egg increase. Given there is no lag between interannual variation of age- 0 abundance and egg production in the simulation (Fig. 4a), this implicates that variation in egg production was due the average weights of age- 1 and age- 2 that are the main contributors to annual egg production. During the 1970s, age-1 growth rate showed sharp drops in 1972 and 1976 (Fig. 4b). As a result of lower age-2 weight, hence lower reproductive output, egg production in 1973 and 1977 were almost the same as the previous years (Fig. 4a) despite the continuous increase in annual egg production over time in the simulation.

\section{Simulated age- 0 and stage-specific survivals}

We focus our analysis on age- 0 survival, which is the determinate of recruitment rate that showed a negative response in anchovy after the 1977 regime shift. We compare the age-0 survival (eggs to recruitment at age-1) with the survival fractions during each of the 

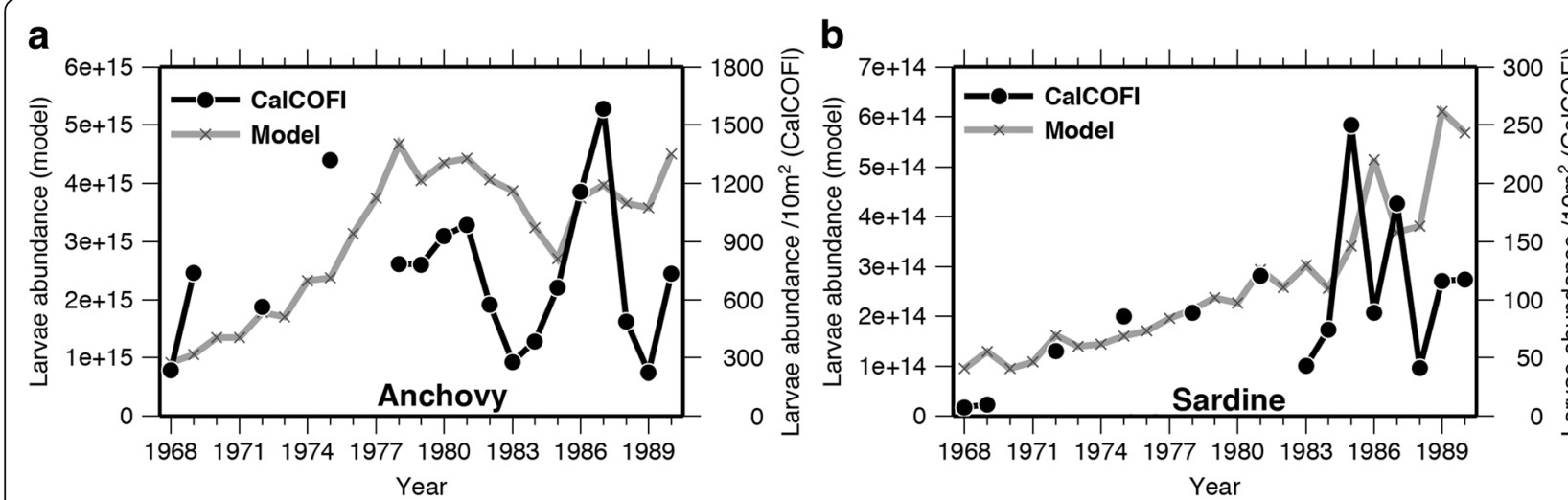

Fig. 3 Comparison between model simulation results and field data for larval abundances. Time series of the larval abundance generated by the climate-to-fishery model (black line with closed circles) and from CALCOFI field data (gray line with open circles) for $\mathbf{a}$ anchovy and for $\mathbf{b}$ sardine

egg-yolk-sac, larva, and juvenile stages. Stage survival is the ratio of the sum of worth of individuals existing a stage to the sum of worth entering the same stage, expressed as a percentage. For anchovy, age-0 survival shows three negative drops: 1972 to 1973, 1976 to 1977, and 1982 to 1983 (Fig. 5a). 1972-1973 drop occurs only in egg-yolk-sac stage survival (Fig. 5b), and 1976-1977 and 1982-1983 drops only occur in larval stage survival (Fig. 5c). Caution is needed in interpreting simulated juvenile stage survival because the stage ends on December 31 of each year, so prolonged larval stage would cause a shortened juvenile stage regardless of the dynamics of growth and mortality during the juvenile stage. A better proxy for the interannual differences in conditions experienced by the juveniles is their average growth rate, which is not influenced by a forced ending day for the stage. Juvenile growth rate for anchovies (Fig. 5d) shows, at best, a weak correspondence to age-0 survival. While 1983 has low juvenile growth rate, the value for 1977 was intermediate and the lowest value was for 1972 that has among the highest age-0 survival.
The only significant positive correlation $(r=0.89, P<$ 0.001 , d.f. $=18, t$ test $)$ between overall age- 0 survival and stage-specific survivals is for the larval stage. Average age-0 survival from 1967 to 1976 is $0.00106 \%$ and then a lower value of $0.00086 \%$ from 1977 to 1986 . Thus, the age-0 survival drops by $19 \%$ from before to after the regime shift. The survival decline during the larval stage is from 0.061 to $0.046 \%$, or a decrease of about $24 \%$. The larval duration becomes longer after 1977 (Fig. 6a), which is caused by a lower growth rate that decreases stage survival. Our analysis shows that the 1976-1977 regime shift has a negative effect on the age-0 survival of anchovy through the slower growth causing a decrease in larval stage survival.

For sardine, correlation analyses between age-0 survival and egg-yolk-sac stage survival, larval stage survival, or juvenile stage survival also suggest that the larval stage survival is most influential for causing interannual variation in the age-0 survival (Fig. 7). As with anchovy, larval stage survival (Fig. 7c) has a significant correlation $(r=0.88, P<0.001$, d.f. $=18, t$ test $)$ with duration of the stage (Fig. $6 \mathrm{~b}$ ), and juvenile growth rate also
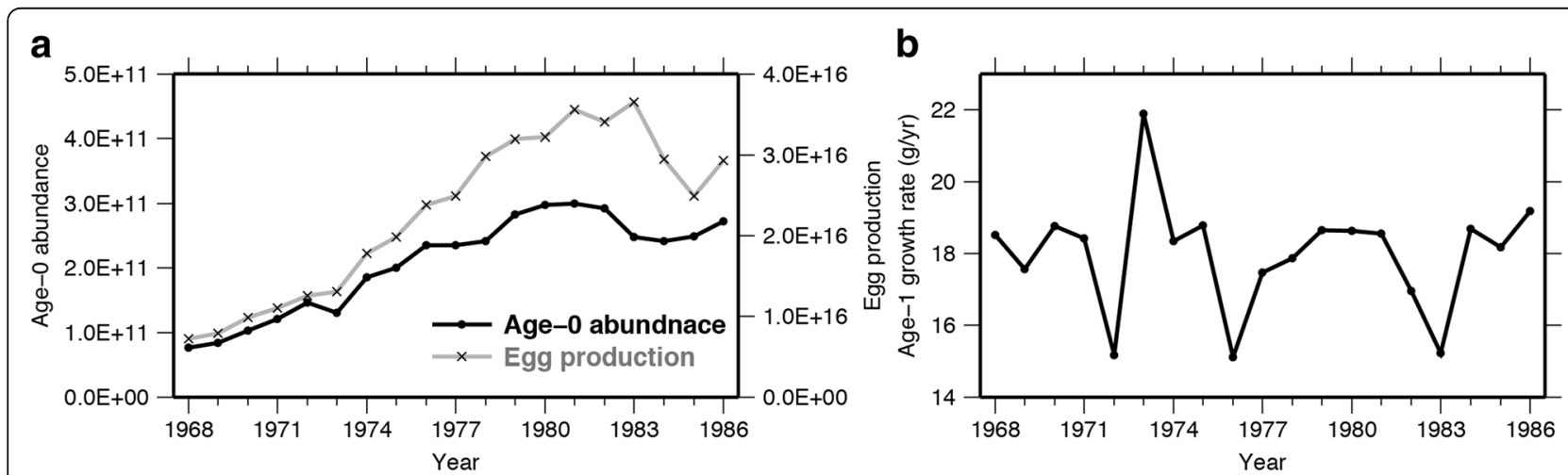

Fig. 4 Time series of simulated $\mathbf{a}$ anchovy age-0 abundance (black line with closed circles) and egg abundance (gray line with crosses) and $\mathbf{b}$ yearly growth rate of age-1 
a

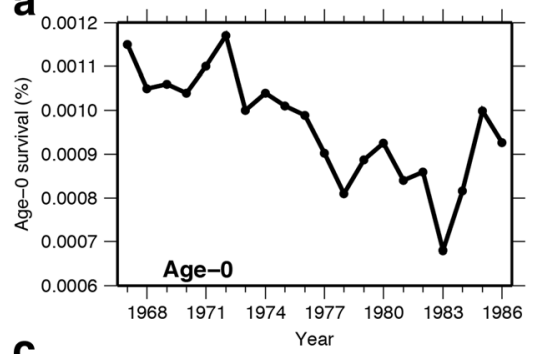

C

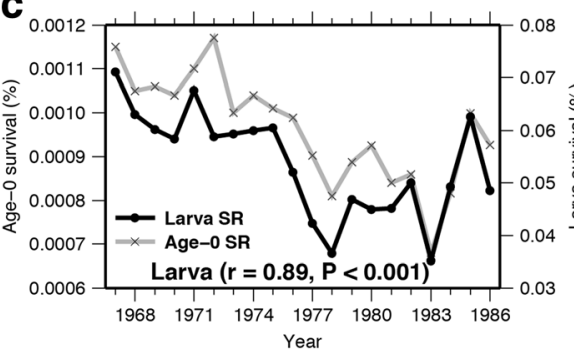

b

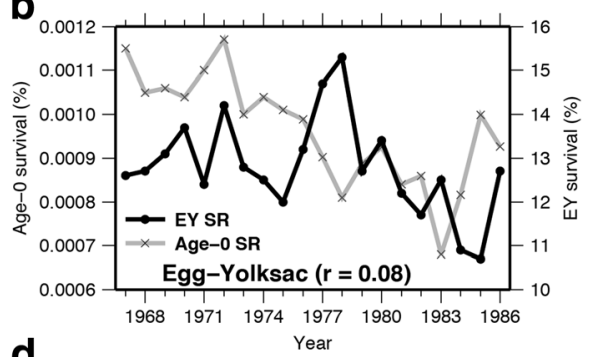

d

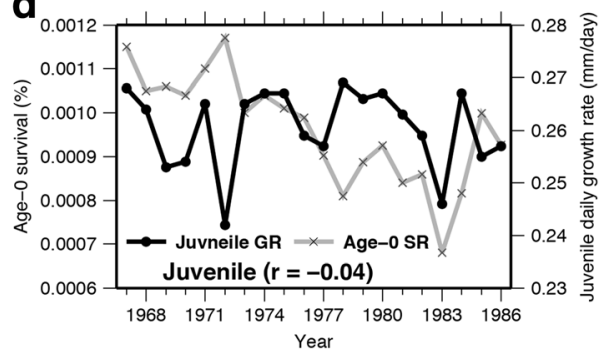

Fig. 5 Time series of simulated anchovy age-0 and stage-specific survivals. Age-0 survival is shown in a as black line and the other panels as a gray line. b Egg-yolk-sac stage survival (black line with closed circles), c larval stage survival (black line with closed circles), and $\mathbf{d}$ juvenile daily growth rate (black line with closed circles) from 1967 to 1986 of the historical simulation

did not show a strong relationship to age-0 survival (Fig. 7d). However, in contrast to anchovy, there are no significant changes in the sardine age-0 survival (Fig. 7a), and other stage survivals including the larval stage (Fig. 7c), corresponding to the 1977 (or 1983) drops seen in anchovy age- 0 and larval stage survival. At least for the simulated dynamics, age- 0 survival of sardine did not show any consistent differences between before versus after the 1977 regime shift.

\section{Coastal larvae and offshore larvae}

While the simulated anchovy larvae distribution focuses on the coastal region, the simulated sardine larvae distribution extends from the coastal region to the offshore region (Fig. 8). On average over the historical simulation, $79 \%$ of the larvae are coastal for anchovy while only $31 \%$ are coastal for sardine. Simulated anchovy larvae are present from late January to early May and sardine larvae occur later, typically from March to July. Larval stage survival of coastal sardine larvae shows a slow decrease after 1977 (Fig. 9, black line). This decline is judged to be a "regime shift" by the regime shift detection test. The decline of the larval stage survival between $1967-1976$ and $1977-1986$ is $15.6 \%$. The decline is smaller than the decline of anchovy larval stage survival (Fig. 5c). Survival of the offshore sardine larvae does not show such a regime shift like change (Fig. 9, gray line). However, these changes in larval stage survival did not propagate through to age- 0 survival or recruitment rate, because relatively few sardine larvae are found in the coastal habitat.

\section{Factors controlling the interannual larval survival}

Hereafter, we focus on the interannual variation of the larval stage. Larval mortality is determined by the growth, which is controlled by food availability and
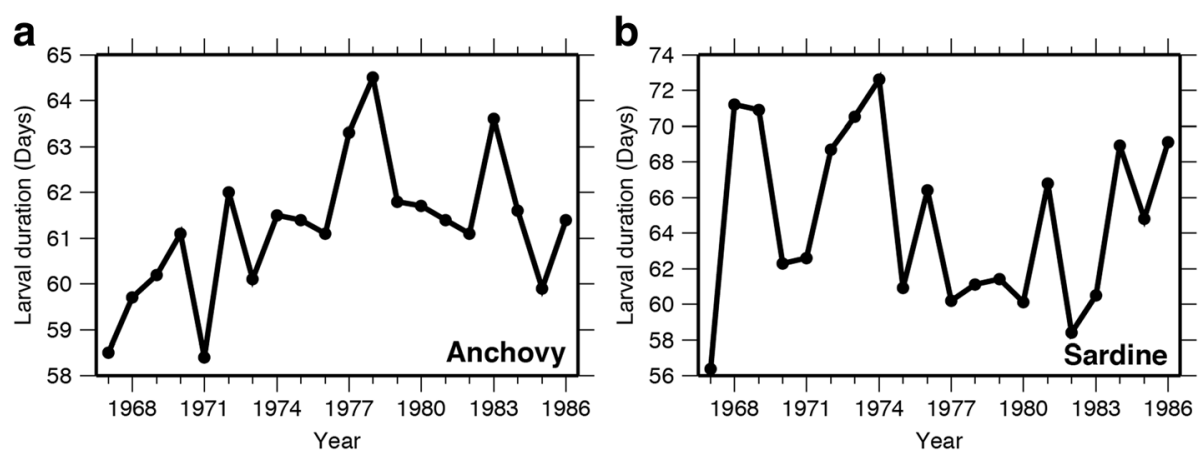

Fig. 6 Time series of simulated a anchovy larval duration and $\mathbf{b}$ sardine larval duration for 1967 to 1986 of the historical simulation 
a
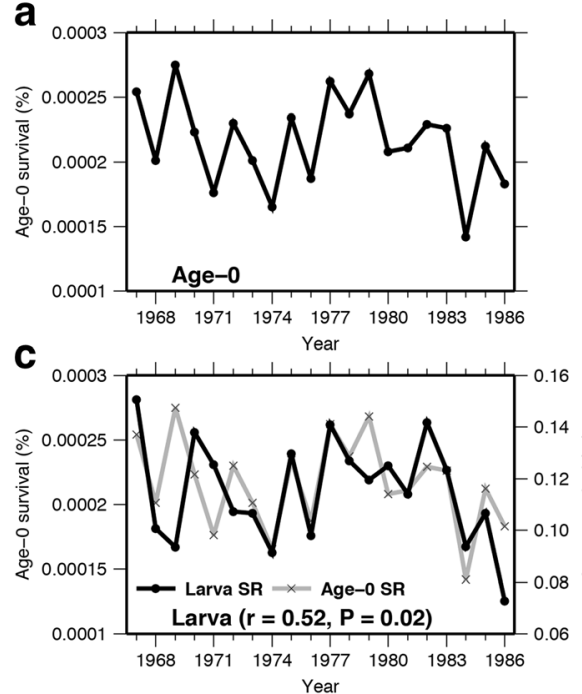

Year

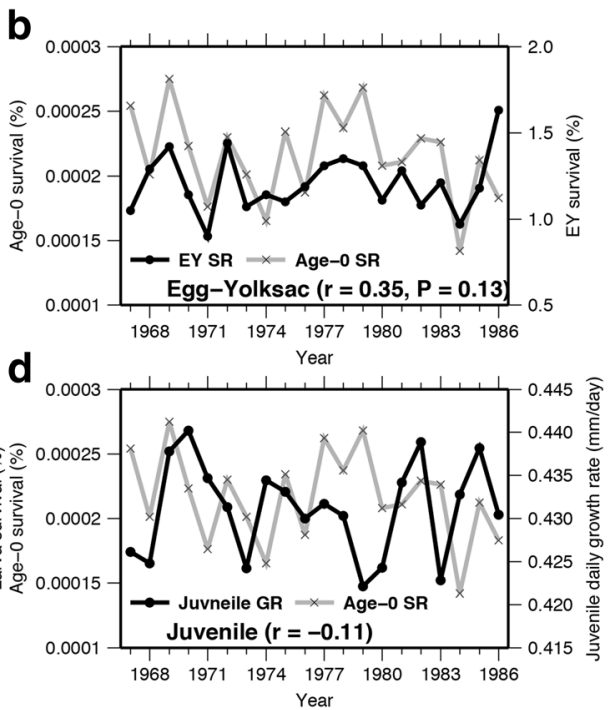

Fig. 7 a-d Same as Fig. 5 but for sardine

temperature. We compare the time series of larval stage survival with ambient zooplankton, which is calculated by daily zooplankton densities interpolated to the exact 3D position of each larva. Anchovies eat small and large zooplankton, while sardines only eat small zooplankton. The ambient small and large zooplankton densities correlate with the larval stage survival of anchovy (Fig. 10a and b). The correlation coefficients between stage survival and small and large zooplankton densities are 0.86 $(P<0.001$, d.f. $=18)$ and $0.91(P<0.001$, d.f. $=18)$. Ambient zooplankton densities exhibit significant changes after 1977. The declines in means from 1967-1976 to 1977-1986 are $0.026 \mathrm{mmol} \mathrm{N} / \mathrm{m}^{3}$ (10.5\%) for small zooplankton and $0.027 \mathrm{mmol} \mathrm{N} / \mathrm{m}^{3}(12.3 \%)$ for large zooplankton. The ambient zooplankton density for sardine also has significant positive correlation with the stage survival of both coastal and offshore sardine larvae
(Fig. 10c and d). Corresponding to the drop in survival of the coastal sardine larvae, the ambient zooplankton density on the coastal sardine feeding grounds decreases around mid-1970s (Fig. 10c). The decline in mean densities between $1967-1976$ and $1977-1986$ is $0.018 \mathrm{mmol} \mathrm{N} / \mathrm{m}^{3}$ (9.0\%), which is smaller than the declines simulated for anchovy. Though warmer ocean temperatures could also lead to higher growth, the model results show no significant correlations between ambient temperature (computed similarly as zooplankton densities) and larval stage survival for anchovy and coastal or offshore sardine from the late 1960s to early 1980s (not shown). These results suggest that food availability is a main factor controlling interannual variation of the larval stage survival for both anchovy and sardine. The decrease of the ambient zooplankton density in anchovy habitat after the regime shift causes lower survival of anchovy larvae. Ambient zooplankton density of sardine
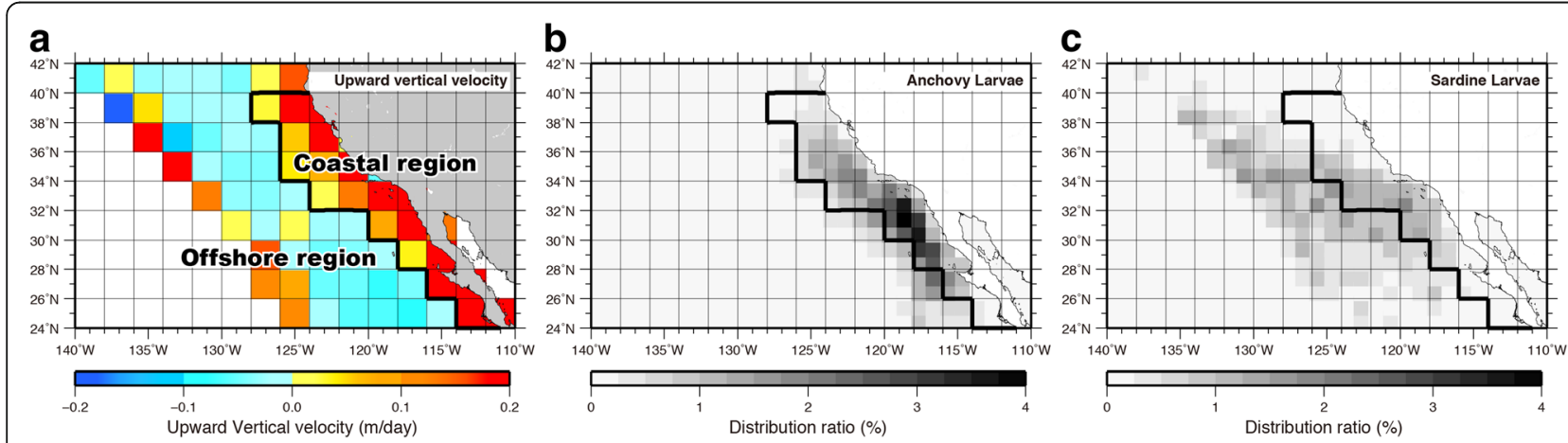

Fig. 8 Simulated horizontal spatial distributions of anchovy and sardine larvae averaged over the historical simulation. a Distribution of the vertical velocity and the boundary between the coastal region and offshore region denoted as black lines. Upward velocity was positive. b Distribution ratio during larval stage for anchovy and $\mathbf{c}$ for sardine. Distribution ratio was calculated based on the location of each super-individual and weighted by its abundance 


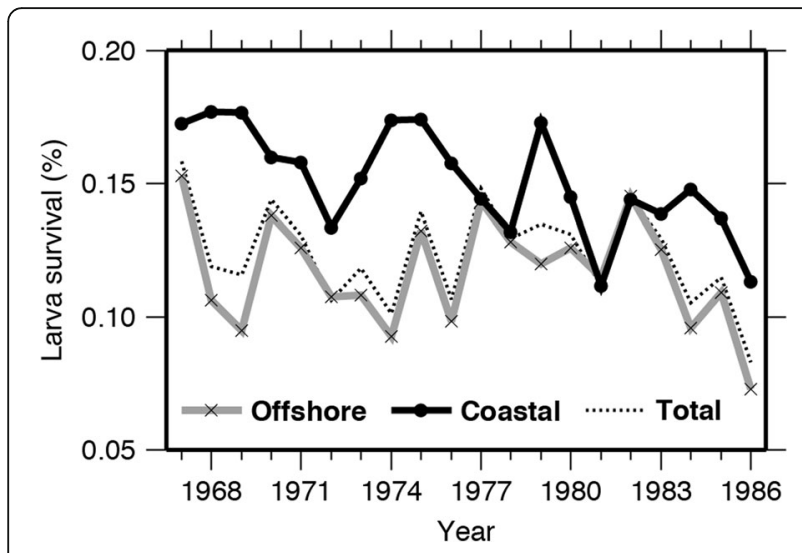

Fig. 9 Time series of simulated sardine larval stage survival. Offshore sardine larvae (gray line with crosses), coastal sardine larvae (black line with closed circles), and all sardine larvae (broken line) from 1967 to 1986 of the historical simulation

that feed in the same coastal region as anchovy also shows a weak regime shift, while the prime habitat for sardine larvae (offshore) did not show a significant zooplankton regime shift and so the larval stage survival of offshore sardine larvae did not show a regime shift signal.

\section{Regime shift of the plankton and nutrients in the coastal region}

There are two possible mechanisms in the model that changed the ambient zooplankton densities for anchovy and for coastal sardine larvae during 1976-1977. One is a change of zooplankton density itself and the other is a change of spatial or seasonal distribution of the larvae. We cannot find any larval distribution pattern changes that seemed likely to result in a decrease ambient zooplankton density experienced by the larvae around mid-1970s. On the other hand, simulated zooplankton density near the coastal region shows a decline in 1977 (Fig. 11). Thus, zooplankton density itself decreased in the feeding grounds of anchovy and coastal sardine larvae.

There is a notable feature in spatial distribution pattern in the coastal zone associated with this negative regime shift, which rarely occurs in the offshore region. The frequency of detection of negative regime shifts in the coastal area was exceptionally high for 1977. Negative regime shifts occur widely from January to May (typified by February in Fig. 11), but shows much lower occurrences beginning in June (Fig. 11). Detailed monthly changes in the distribution of regime shift detections are shown in Additional file 2: Figure S1, Additional file 3: Figure S2 and Additional file 4: Figure S3. We note that the location and season of the zooplankton regime shift, winter-early spring in the coastal region, overlap with main feeding grounds of the anchovy larvae. However, the feeding grounds of sardine larvae are only partially affected.

In the NPZ model, one of the controlling factors of zooplankton density is the flux of nitrate and silicate from nutrients to zooplankton through phytoplankton production. The same regime shift detection around 1977 in zooplankton density shows that both phytoplankton and nitrate
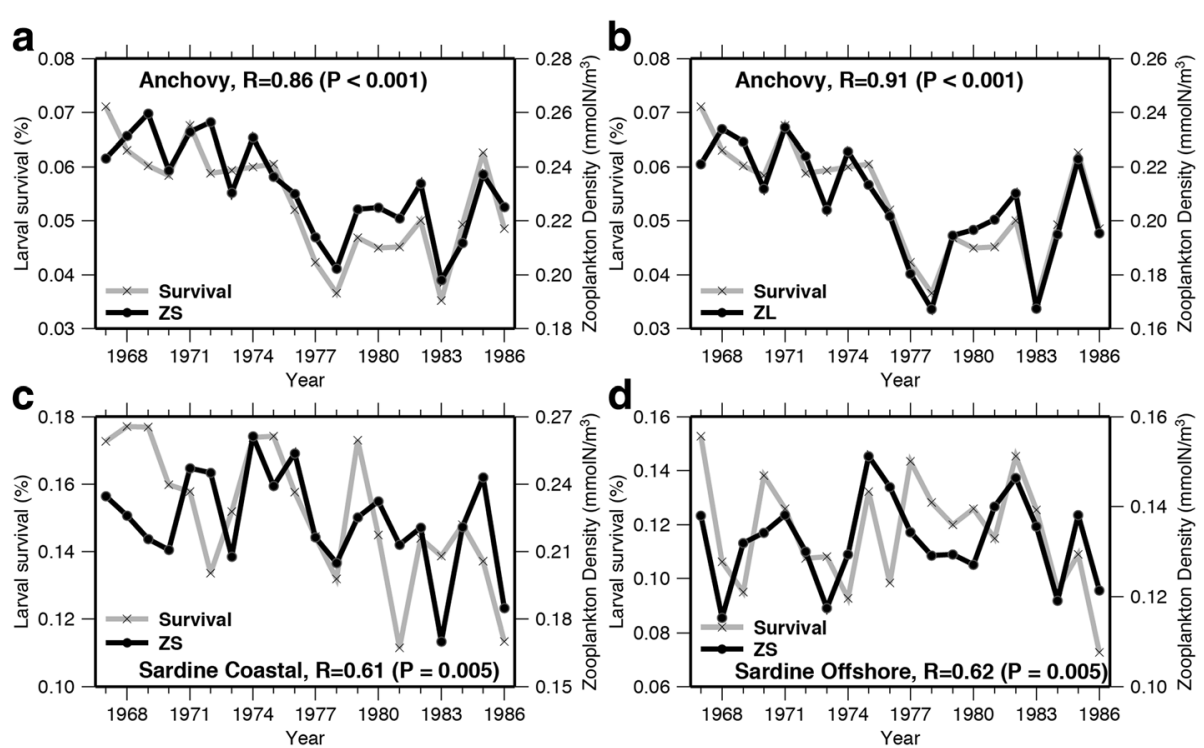

Fig. 10 Comparison between larval stage survival of anchovy and sardine and zooplankton densities. Time series of simulated a ambient small zooplankton (ZS) density (black line with closed circles) and larval stage survival of anchovy (gray line with crosses), b ambient large zooplankton (ZL) density and anchovy larval survival, c ambient ZS density and larval stage survival of coastal sardine, and $\mathbf{d}$ ambient ZS density and larval stage survival of offshore sardine. $R$ denotes the correlation coefficient, and $P$ denotes the probability value. Zooplankton density is the values recorded concurrently as what each larval individual experienced and is averaged accounting for the worth of the different super-individuals 


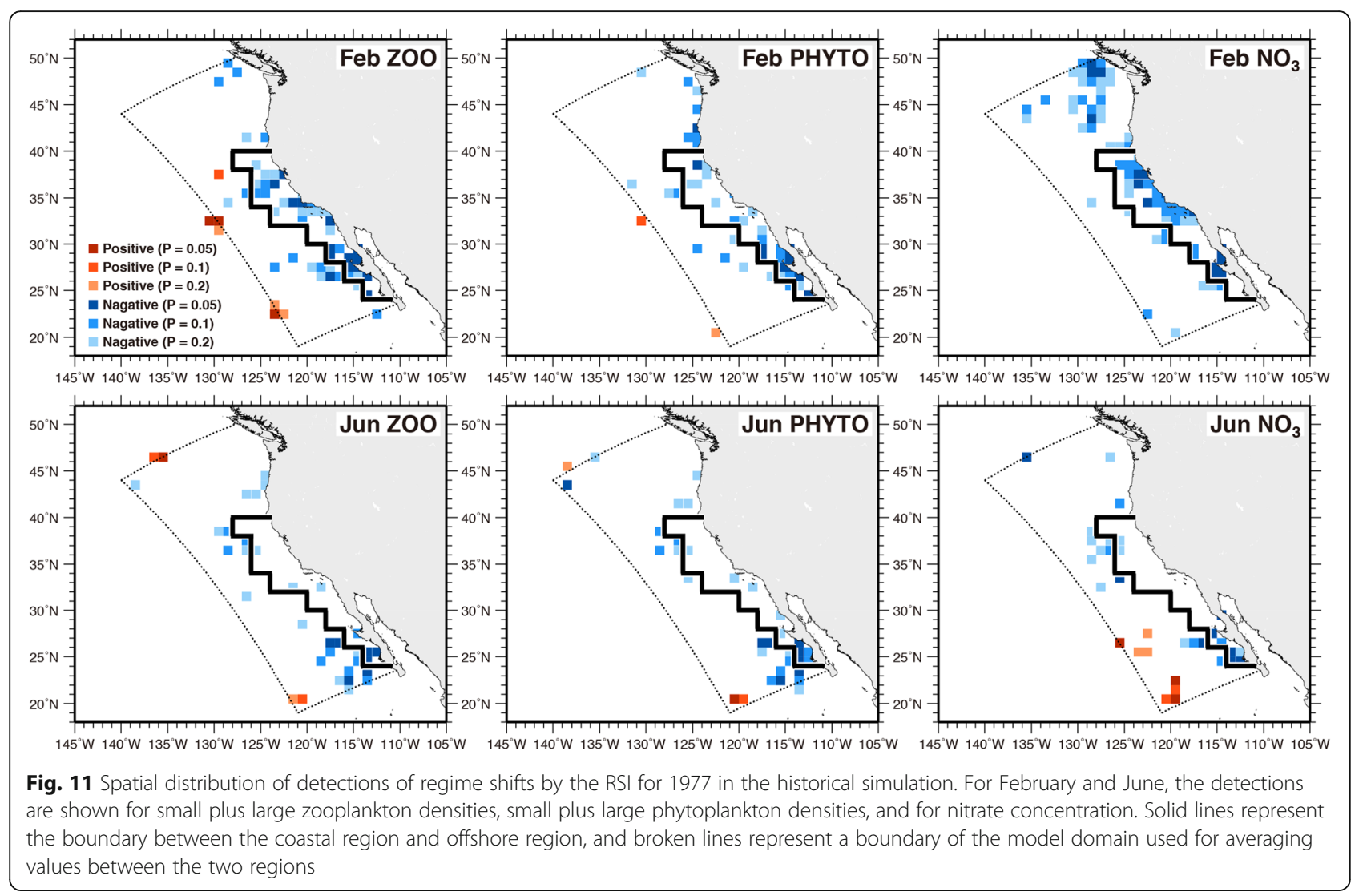

also decreased in the coastal region from winter to early spring (Fig. 11). Temperature was a controlling factor for phytoplankton growth in the model, and the MLD affected phytoplankton growth via changes in primary controlling factors, such as temperature, light exposure, and nutrient availability. After 1977, temperature rose and MLD decreased in the coastal region during winter to early spring (Fig. 12a). The MLD averaged from January to April decreased by $2.4 \mathrm{~m}$ between 1967-1976 and 19771986 , and the maximum depth decreased by $2.5 \mathrm{~m}$. This decrease implies that temperature and light conditions, which are depending on averaged MLD, were favorable for phytoplankton growth after the 1977 regime shift. Averaged nitrate concentration in the coastal region from January to April, averaged over the upper $30 \mathrm{~m}$ of the water column, decreases by $0.88 \mathrm{mmol} \mathrm{N} / \mathrm{m}^{3}$ (7\%) between 1967-1976 and 1977-1986 mean (Fig. 12b) and ammonium and silicate concentrations also showed similar decreases after 1977 (Fig. 12c and d). The decline of nutrients resulted in an average decrease of $0.06 \mathrm{mmol} \mathrm{N} / \mathrm{m}^{3}(16 \%)$ of phytoplankton (Fig. 12e) leading to an average decrease of $0.08 \mathrm{mmol} \mathrm{N} / \mathrm{m}^{3}$ (21\%) in zooplankton density (Fig. 12f).

\section{Regime shift effects on nutrient supply}

There are three main nutrient supply routes to the coastal surface layer: horizontal advection, vertical advection, and vertical diffusion. Horizontal diffusion is small enough to be negligible when compared to the other two factors. We compare the nitrate supply into the coastal upper $30 \mathrm{~m}$ of the water column across the lateral and bottom boundary by the three supply processes from before the regime shift (1967-1976) to the period after (1977-1986) between October and June. The supplied nutrients are not always immediately taken up for photosynthesis. The autumn nutrient 1 year prior affects the nutrient concentration in winter. The total nitrate supply from December to April decreases after the regime shift, but then increases during May to June (Fig. 13a). The significant difference between before and after the regime shift is shown from December to January and in April. This result is consistent with the former analysis that the negative nitrate regime shift disappears after May.

The nitrate supply by vertical advection shows a similar seasonal change as the total nitrate supply, and with a larger reduction between 1967-1976 and 1977-1986 (Fig. 13b). The significant difference between before and after the regime shift is shown from October to January and in April. In December, while the vertical advection is positive before 1977, the vertical advection is negative after 1978 . The negative value implies that nitrate is removed from the coastal surface layer. The nitrate supply due to horizontal advection and by vertical diffusion 

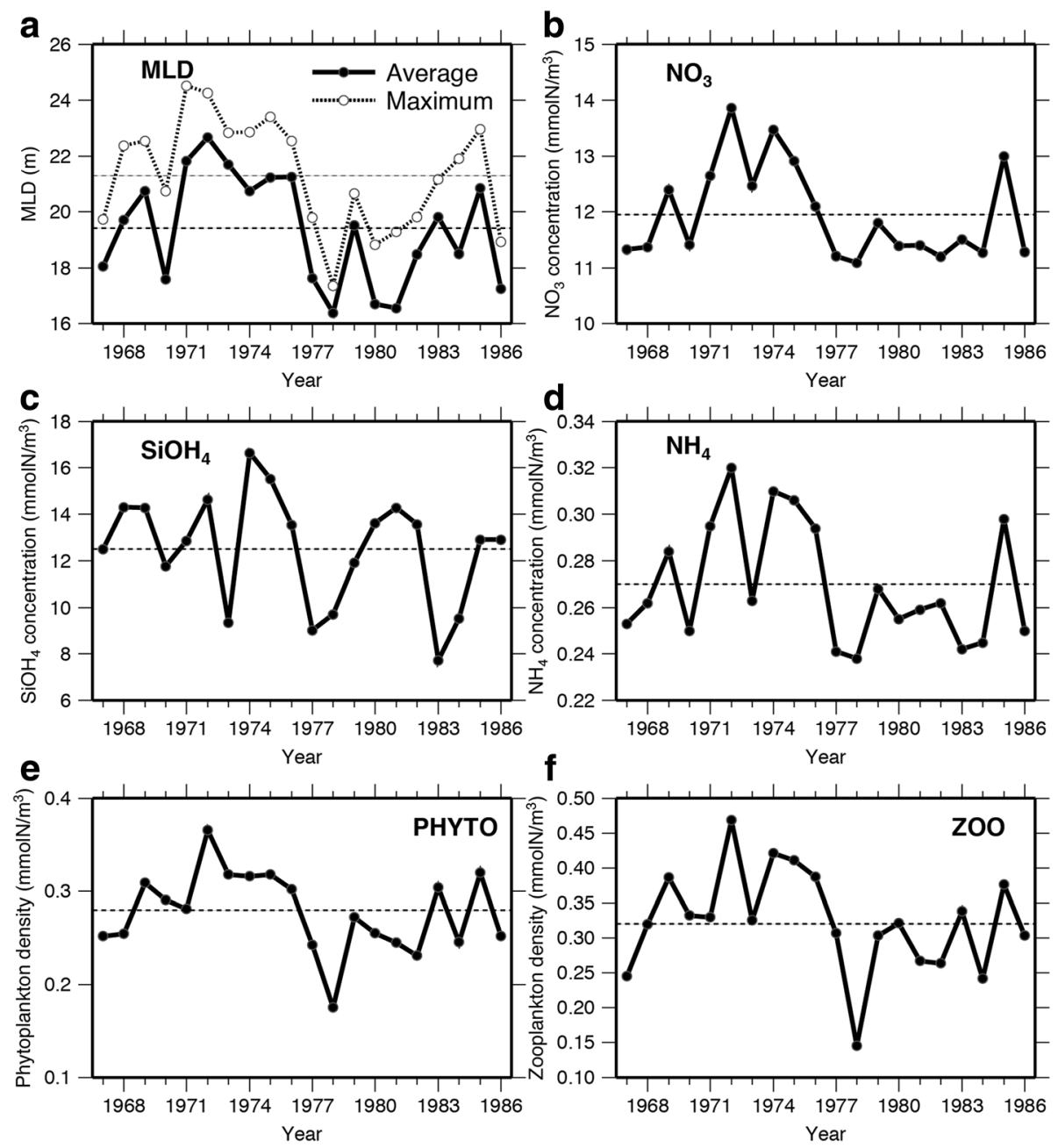

Fig. 12 Time series of selected physical and biological variables, a average and maximum mixed layer depth, b nitrate concentration, c silicate concentration, $\mathbf{d}$ ammonium concentration, e small plus large phytoplankton density, and $\mathbf{f}$ small plus large zooplankton density from the historical simulation. Values are averaged in the coastal region from January to April for $\mathbf{a}-\mathbf{f}$, and broken line represents the averaged value from 1967 to 1987. Nutrients and planktons are averaged in the upper $30 \mathrm{~m}$ of the water column, the main habitat of the anchovy and sardine larvae

increases after the regime shift (Fig. 13c and d). Figure 14 shows the time series of nitrate supply integrated from October to April. The total nitrate supply and the nitrate supply by vertical advection drop in 1977 (Fig. 14a and b), but there is no drop in 1977 for the nitrate supply due to horizontal advection and by vertical diffusion (Fig. 14c and d). Since the nitrate supply by vertical advection decreases $1.02 \times 10^{14} \mathrm{mmol} \mathrm{N}$ from average 1967-1976 mean to 1977-1986 mean, the total nitrate at the same period decreases $6.96 \times 10^{13} \mathrm{mmol} \mathrm{N}$. Thus, the seasonal and interannual variation of the total nitrate supply mostly depends on the vertical advection, which after the regime shift, decreases during autumn to early spring in the coastal region. Given that silicate supply is also mostly controlled by the vertical advection and that the main source of ammonium is nitrification, the same vertical advection effects applies to all nutrients.
Nutrient-rich subsurface water is introduced into the surface layer in the model by two processes: deepening of the seasonal mixed layer and the upward movement of a volume of water (upwelling). The maximum depth of winter mixed layer becomes shallow after the regime shift in the coastal region (Fig. 12a), causing a reduction in the nutrients available to phytoplankton in the mixed layer.

In the CCS, there are two types of upwelling: coastal upwelling and the curl-driven upwelling. The mean volume of the coastal upwelling $\left(8.2 \times 10^{12} \mathrm{~m}^{3}\right)$ in the simulation is 13 times larger than that of the curl-driven upwelling $\left(6.0 \times 10^{11} \mathrm{~m}^{3}\right)$ (Fig. 15). Coastal upwelling was reduced in the simulation in autumn of 1976 and winter of 1977. From October to April, the coastal upwelling decreased from $9.0 \times 10^{12} \mathrm{~m}^{3}$ (1967-1976 mean) to $7.3 \times 10^{12} \mathrm{~m}^{3}$ (1977-1986 mean) 

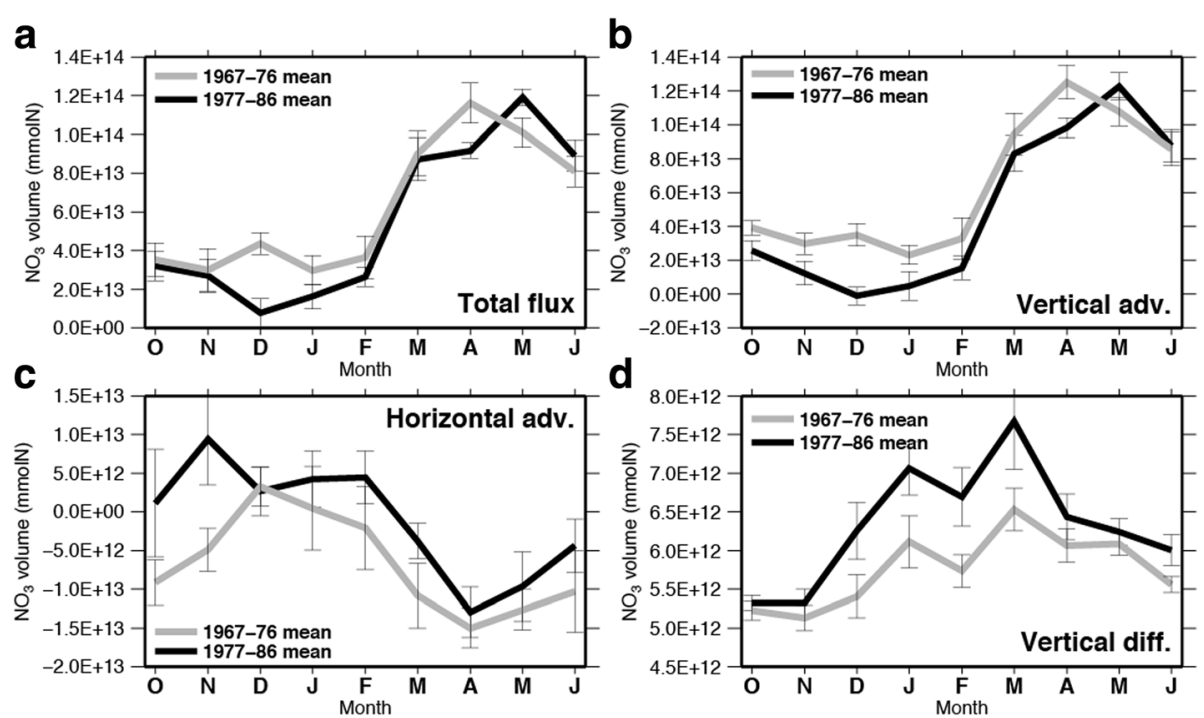

Fig. 13 Simulated seasonal changes of nitrate supply for before and after the regime shift in 1977. a Total nitrate supply, b nitrate supply by vertical advection, c nitrate supply by horizontal advection, and $\mathbf{d}$ nitrate supply by vertical diffusion into the coastal upper $30 \mathrm{~m}$ of the water column. Black line with closed circles represents 1966-1975 mean for October-December and 1967-1976 mean for January-June. Gray line with crosses represents 1976-1985 mean for October-December and 1977-1986 mean for January-June. Error bar represents the standard error. The positive/negative value denotes that nitrate increases/decreases in the coastal upper $30 \mathrm{~m}$ of the water column

(Fig. 15a). Contrary to the coastal upwelling, there is not a significant change during the mid-1970s for the curl-driven upwelling (Fig. 15b). Our analyses show that both the change in MLD and coastal upwelling caused the reduced vertical nutrient supply in the regime shift.

\section{Regime shift of the heat flux and the wind stress}

We investigate the historical simulation for interannual variation of the heat flux and the wind speed in the coastal region between October and April. While we do not find a step-like regime shift in the upward net heat flux, there is a noticeable drop in 1977. Average net heat
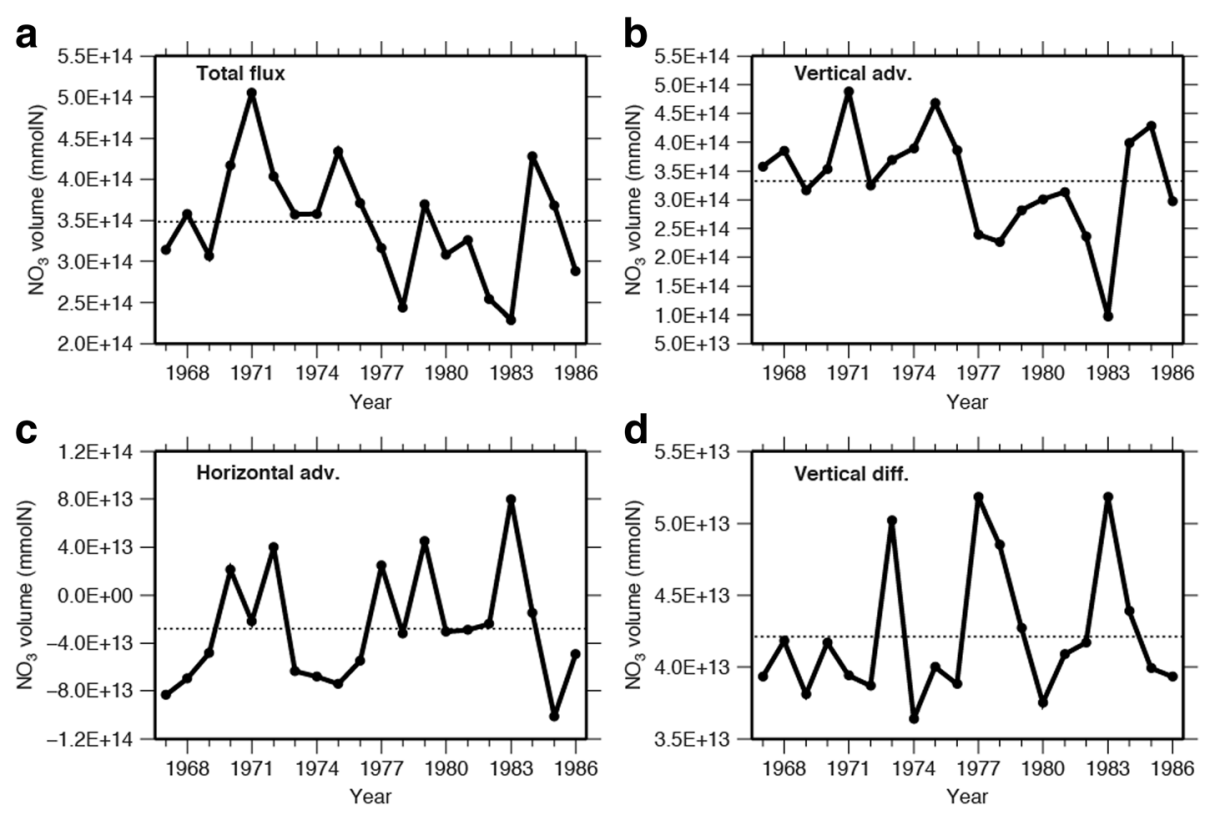

Fig. 14 Simulated time series of nitrate supply for 1967 to 1986 of the historical simulation. a Total nitrate supply, b nitrate supply by vertical advection, c nitrate supply by horizontal advection, and $\mathbf{d}$ nitrate supply by vertical diffusion into the coastal upper $30 \mathrm{~m}$ of the water column integrated from October to April. Broken lines represent the values averaged over 1967 to 1986 

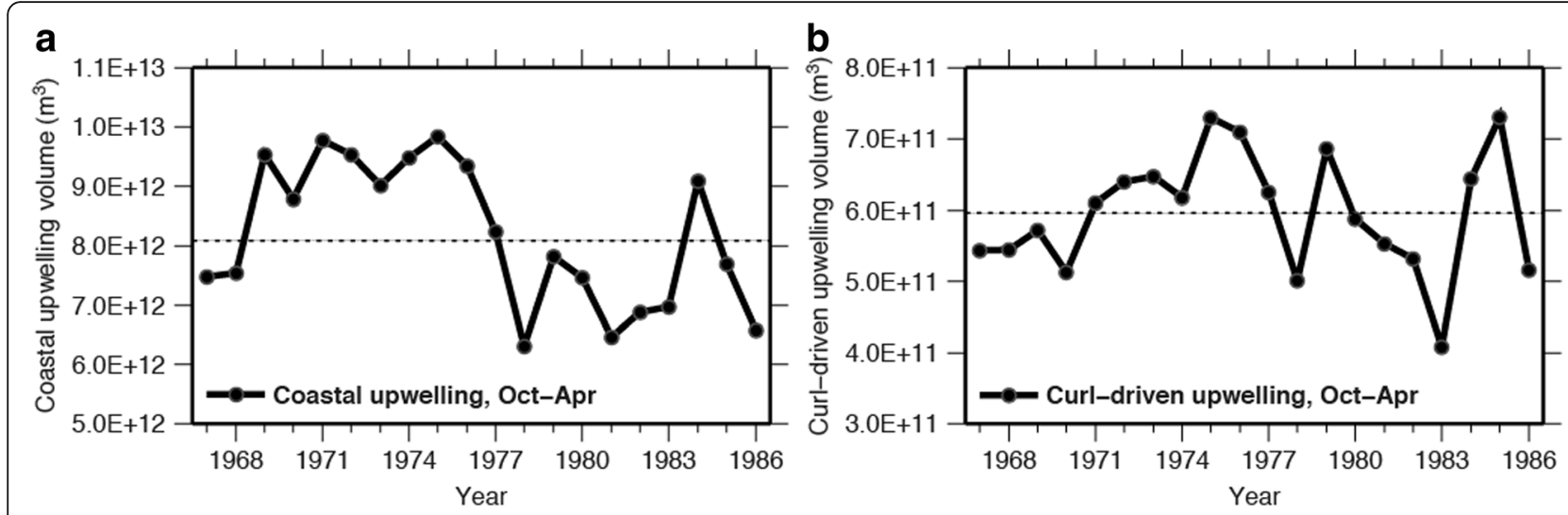

Fig. 15 Simulated time series of upwelling volumes for 1967 to 1986 of the historical simulation. a The coastal upwelling and $\mathbf{b}$ the curl-driven upwelling integrated from October to April. The values from October to December are grouped with the following year. Broken lines represent the values averaged over 1967 to 1986

flux decreases by $26.7 \mathrm{~W} / \mathrm{m}^{2}$ between $1967-1976$ and 1977-1986 (Fig. 16a). Thus, it is possible that weakened cooling from autumn to early spring after 1977 enhanced the stratification.

Net heat flux is composed of sensible heat flux, latent heat flux, short-wave radiation flux, and long-wave radiation flux. Time series of each flux is shown in Fig. 16b and c. Among them, only the sensible heat flux decreased after 1977 (Fig. 16b, black line with closed triangles). The reduction of the sensible heat flux $\left(35.4 \mathrm{~W} / \mathrm{m}^{2}\right.$ from 1967-1976 to 1977-1986) resulted in a weak cooling. Sensible heat flux is mainly controlled by a sea surface absolute wind speed and the difference between sea surface temperature and atmospheric temperature. A regime shift from positive to negative phase in 1977 for the absolute wind speed in the simulation and the speed decreases from an average of $5.4 \mathrm{~m} / \mathrm{s}$ during 1967-1976) to $5.2 \mathrm{~m} / \mathrm{s}$ during 1977-1986 (Fig. 17a). On the other hand, the difference of temperature between sea surface and atmosphere does not have a regime shift or specific decrease in 1977 (Fig. 17b). These results suggest that the weakened absolute wind speed in the simulation causes a weak cooling, strong stratification, and shallower MLD. Using Eq. 6, this difference of $0.2 \mathrm{~m} / \mathrm{s}$ would generate about a 4-m difference in MLD during February, which is comparable to the $2.5 \mathrm{~m}$ decrease of the maximum MLD during the historical simulation (Fig. 12a).

The reduced coastal upwelling itself, together with the MLD shoaling, causes the nutrient regime shift in the historical simulation. Alongshore wind speed that controls the coastal upwelling shifts from strong phase to weak phase in 1977 (Fig. 18) the same as the absolute wind speed (Fig. 17a). The notable difference between the mean wind speed before regime shift and that after the regime shift appears clear from late November to April in both wind speeds (Fig. 19). This seasonal variation is consistent with the result that the regime shift reduced vertical nutrient flux (Fig. 13) and lowered surface nutrient concentrations occurred from winter to early spring (Fig. 11). Thus, as the background of the nutrient regime shifts, there is a decrease of the wind speed from late autumn to early spring in the coastal region including the near shore region.
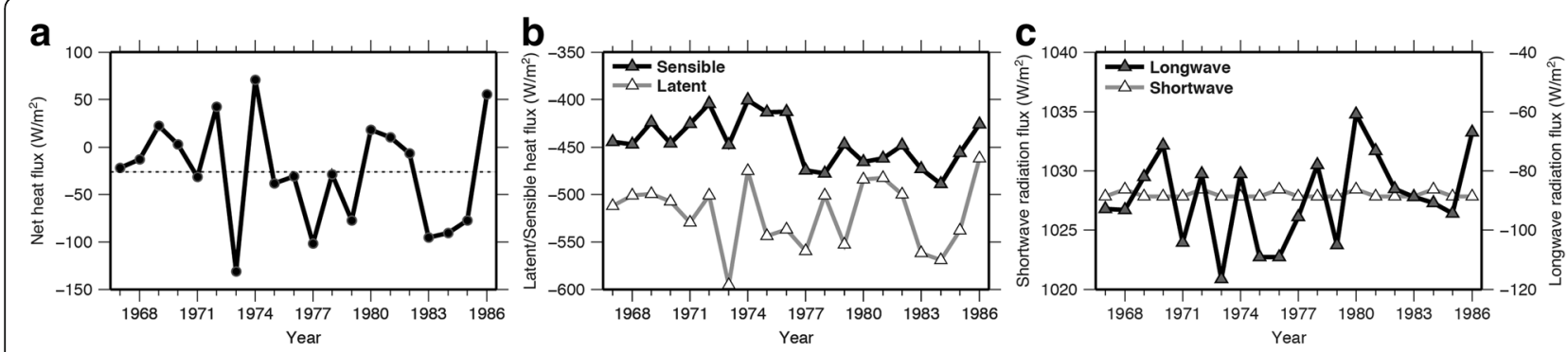

Fig. 16 Simulated time series of heat flux for 1967 to 1986 of the historical simulation. Values are averaged from October to April for a net heat flux, $\mathbf{b}$ sensible heat flux (black line with closed triangles) and the latent heat flux (gray line with open triangles), and $\mathbf{c}$ longwave radiation flux (black line with closed triangles) and short-wave radiation flux (gray line with open triangles) averaged from October to April. The values from October to December are grouped with the following year. Broken line in a represents the net heat flux averaged over 1967 to 1986 

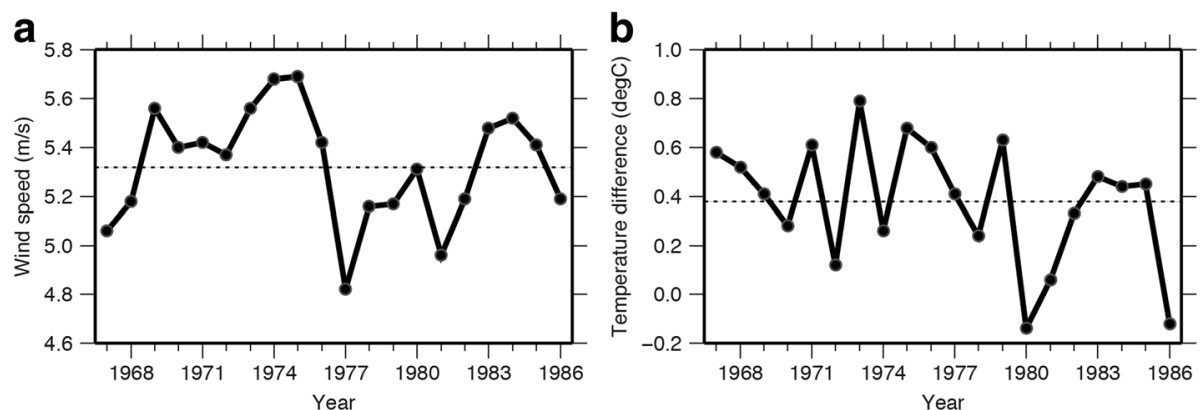

Fig. 17 Time series of wind and difference of temperature used as input to the historical simulation. Values are averaged from October to April for $\mathbf{a}$ the absolute wind speed and $\mathbf{b}$ the difference of temperature between sea surface and atmosphere. The values from October to December are grouped with the following year. Broken lines represent average values computed over 1967 to 1986

\section{Discussion}

Possible impact of the 1976-1977 regime shift

We used our analysis of the historical simulation described above to formulate a conceptual diagram on how the 1977 North Pacific regime shift affected anchovy and sardine (Fig. 20). Wind speed, especially the alongshore component, decreased in the California coastal region from late autumn to early spring leading to reduced coastal upwelling. The weak upwelling is linked to the intensity of the stratification. In addition, the reduced absolute wind speed cannot sufficiently cool and mix the surface layer, which results in a relatively shallow mixed layer. Nutrient concentrations decreased due to the weak coastal upwelling and shallow mixed layer, which resulted in a low zooplankton density in the coastal region between winter and spring. The forage decline impacts the stage survival of anchovy larvae that feed mainly in the coastal region. However, while a part of the sardine larvae was under the influence of the coastal forage decline, most sardine larvae fed in the offshore region from spring to summer and were thus less

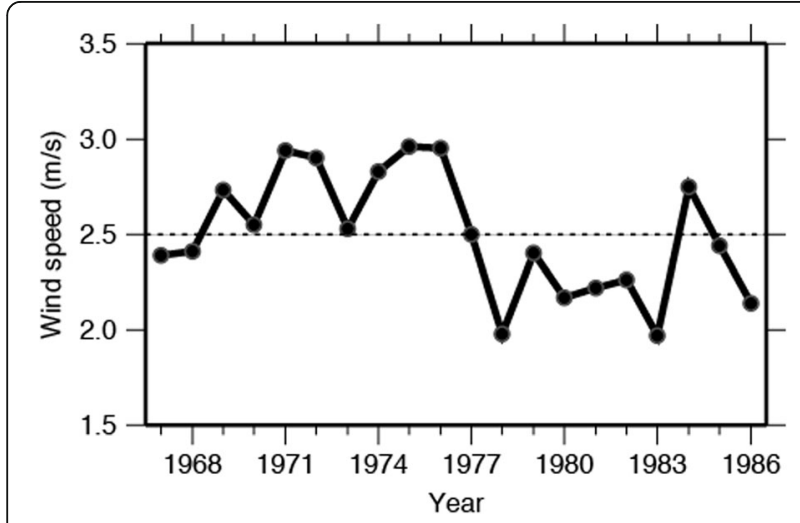

Fig. 18 Time series of alongshore wind speed used as input to the historical simulation. Values are averaged from October to April. The values from October to December are grouped with the following year. Broken lines represent average values computed over 1967 to 1986 exposed to reduced prey availability. This explains why the age- 0 survival of anchovy had become low after the regime shift, while the regime shift had a little impact on the age-0 survival for sardine.

Based on our historical simulation using the climateto-fishery model, we suggest that the influence of the regime shift had both temporal (seasonal) and spatial footprints. The causes emerge due to the different responses to the regime shift by anchovy and sardine in relation to their particular ecology. The possibility that anchovy is more sensitive to changes in coastal upwelling than sardine has been suggested by Rykaczewski and Checkley (2008). This finding is also supported by an earlier analysis using the same model as used here (Fiechter et al. 2015), which found that the primary factor controlling anchovy population abundance in the CCS was changes in egg production associated with varying adult growth conditions (i.e., prey availability) in the coastal upwelling region. Our results support this hypothesis by explaining the underlying process of how the changes in coastal upwelling affected anchovy and sardine. Furthermore, we find that considering temporal variability within the year is crucial for understanding the niche differences between sardine and anchovy (e.g., Fig. 20).

Our simulation is not perfect. The biomass does not reproduce the yearly variation completely, and recruitment rate is smaller than that of observation data. One of the causes of model uncertainty is the parameter value of the individual-based fish model. The biological parameter (e.g., mortality rate) is not a uniquely determined value in the real world. For some parameters, field survey data presented a value range and we chose a value in a range. The historical simulation did not fully reproduce the absolute values (biomass, abundance) and interannual variation of the sardine and anchovy dynamics. Our model is best viewed as a tool for exploring how environmental variation on decadal scales can affect anchovy and sardine recruitment and population dynamics. The model skill of ours is not yet sufficient for use 

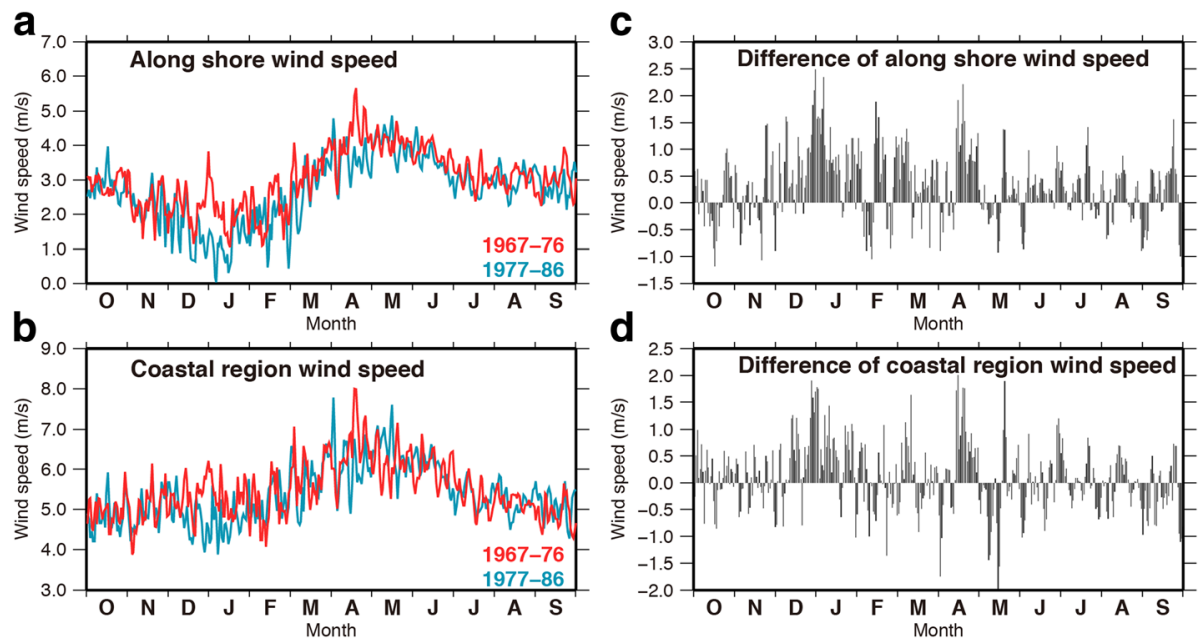

Fig. 19 Seasonal changes of wind used as input to the historical simulation. a Alongshore wind speed within $10 \mathrm{~km}$ of the coastline, $\mathbf{b}$ absolute wind speed in the coastal region, c difference of the alongshore wind speed from 1967-1976 mean to 1977-1986 mean, and d difference of the absolute wind speed in the coastal region from 1967-1976 mean to 1977-1986 mean. In a and $\mathbf{b}$, red line denotes value averaged over 1967 to 1976 and blue line denotes value averaged over 1977 to 1986. The values from October to December are grouped with the following year

for tactical fishery management (Collie et al. 2016). We used the historical simulation here to examine how different physical and biological processes related to the 1977 regime shift combined to affect anchovy and sardine recruitment.

\section{Influence of coastal upwelling}

There are two possible mechanisms for the simulated nutrient decline to the CCS: weakened coastal upwelling and shallowing of the winter mixed layer. While the

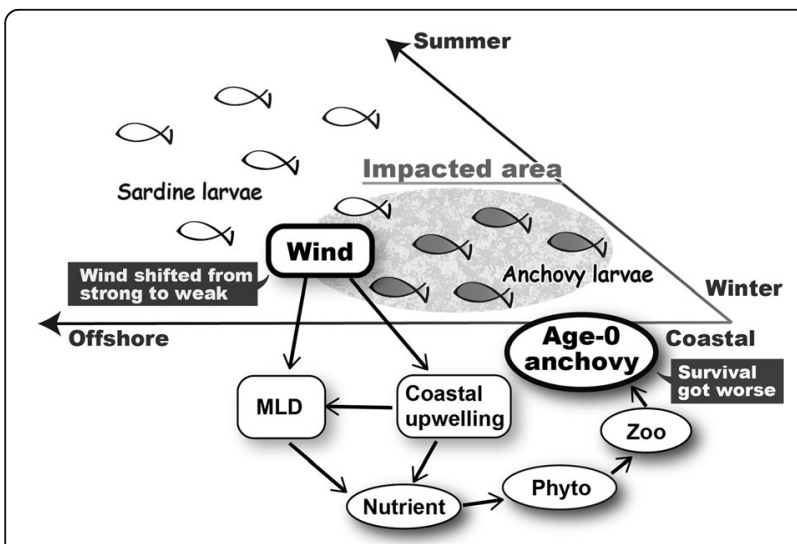

Fig. 20 Conceptual summary of regime shift effects on sardine and anchovy based on the analysis of the historical simulation. Schematic diagram illustrating a chain reaction from the wind regime shift after 1977 to anchovy and sardine dynamics. The weakened wind speed from autumn to early spring links to the low food density in the coastal area, which affects many of the anchovy larvae. Consequently, age-0 anchovy survival is reduced after the regime shift. On the other hand, most of the sardine larvae that were distributed in the offshore region from spring to summer were unaffected by the regime shift coastal upwelling intensity has been regarded as a main controlling factor for productivity in the CCS (e.g., Ryther 1969), impact of stratification (MLD) change on nutrient supply is also significant (Traganza et al. 1987; Jacox and Edwards 2011). However, upwelling and stratification changes are not independent. Both weak coastal upwelling and strong stratification (shallow mixed layer) are caused by weakening of wind, but weak coastal upwelling itself also causes strong stratification. Thus, we considered that the weakening of coastal upwelling is important as direct and indirect factors driving the regime shift in nutrients and consequently in anchovy.

A study of zooplankton decline in the 1976-1977 regime shift by McGowan et al. (2003) did not find a significant correlation between the upwelling index, which is a measure of coastal upwelling, and zooplankton density in the CCS. Our results that the regime shift in the coastal upwelling is only significant between winter and early spring may help refine analyses like McGowan et al. (2003). The importance of upwelling phenology in the CCS for seasonal development of the ecosystem is also confirmed by krill and juvenile rockfish abundance (Schroeder et al. 2014).

Because the coastal upwelling is most active from spring to summer (Garcia-Reyes and Largier 2012), the interannual variation during the weak upwelling season (autumn and winter) may be difficult to detect in observational data. The alongshore wind speed that caused coastal upwelling dropped to near 0 in early winter and sometimes even reversed (Fig. 19a). The difference between upwelling and downwelling can be critical in determining nutrient conditions. Thus, even though the absolute value of alongshore wind speed in winter is not 
large, the interannual variation of the coastal upwelling had a substantial impact on the ecosystem through the nutrient supply.

\section{Conclusions}

The purpose of this study is to investigate the influence of the 1976-1977 regime shift on Northern anchovy and Pacific sardine in the CCS by using a climate-to-fishery model. In the model simulation, the recruitment rate of anchovy decreased after 1977 due to the low survival of larvae, whereas sardine recruitment rate and larval survival did not show such declines. The differences resulted from the seasonal and spatial differences of larval distribution between anchovy and sardine. The anchovy larvae feed extensively from winter to early spring in the coastal region, where the changes in the wind dynamics were strong. After 1977, the absolute wind speed in the coastal region and the alongshore wind speed near shore decreased from autumn to early spring. This led to a decline of zooplankton density from winter to early spring due to poor nutrient supply from the subsurface waters. This reduced prey availability caused low survival of anchovy larvae. On the other hand, since sardine larvae were distributed largely offshore from spring to summer, most of them were less exposed to reduced prey availability.

Our analysis of the historical simulation illustrates the utility of using climate-to-fishery models to identify possible cause-and-effect explanations for the population dynamics of sardine and anchovy and other species. The model generates a consistent and comprehensive dataset (model output) on the 3D dynamics of physics, nutrients, phytoplankton, zooplankton, and fish that would be impossible to obtain with field data. Of course, as with all complicated ecosystem-based models, there are many assumptions and caveats that need to be considered when interpreting model results. Further analyses should consider additional proposed regime shifts to look for consistency in explanations, investigation into how the 1977 regime shift may have affected the predators and fishery of sardine, and continued testing of the model by comparison to field data to better assess model skill and appropriate levels of confidence in critical model results.

\section{Additional files}

Additional file 1: Table S1. Definition of variables in figures. (DOCX $43 \mathrm{~kb}$ )

Additional file 2: Figure S1. Simulated spatial distribution of detections from the RSI in 1977 for small plus large zooplankton density. Solid lines represent the boundary between the coastal region and offshore region and broken lines represents a boundary of the model domain. This figure is supplemental figure for Fig. 11. (TIF $575 \mathrm{~kb}$ )
Additional file 3: Figure S2. Same as Additional file 2: Figure S1, but for small plus large phytoplankton density. (TIF $17111 \mathrm{~kb}$ )

Additional file 4: Figure S3. Same as Additional file 2: Figure S1, but for nitrate concentration. (TIF $17111 \mathrm{~kb}$ )

\section{Abbreviations}

CalCOFI: California Cooperative Oceanic Fisheries Investigation project; CCS: California Current System; CORE2: Common Ocean-Ice Reference Experiments; DON: Dissolved organic nitrogen; IBM: Individual-based fish model; NEMURO: North Pacific Ecosystem Model for Understanding Regional Oceanography; NPZ: Nitrogen-phytoplankton-zooplankton; Opal: Biogenic silica; PL: Large phytoplankton; PON: Particulate organic nitrogen; PS: Small phytoplankton; ROMS: Regional Ocean Modeling System; RSI: Regime shift index; SODA: Simple Ocean Data Assimilation; ZL: Large zooplankton; ZP: Predatory zooplankton; ZS: Small zooplankton

\section{Acknowledgements}

We would like to acknowledge Dr. David Checkley of Scripps Institution of Oceanography for his valuable comments and suggestions.

\section{Funding}

HN was supported by JSPS KAKENHI Grant-in-Aid for JSPS Fellows Number 15 J01506 and Grant-in-Aid for Early-Career Scientists Grant number 18 K14516.

Availability of data and materials

Please contact the author for data requests.

\section{Authors' contributions}

ENC, JF, KAR, and KH developed the climate-to-fishery model. HN analyzed the model output and wrote the first draft of the manuscript. ENC, JF, and KAR provided ideas for the study and helped in the interpretation of the model output. ENC and KAR collaborated with the corresponding author in the construction of the manuscript through several drafts. All co-authors participated in the discussions about the results and commented on the manuscript. All authors read and approved the final manuscript.

\section{Competing interests}

The authors declare that they have no competing interests.

\section{Publisher's Note}

Springer Nature remains neutral with regard to jurisdictional claims in published maps and institutional affiliations.

\section{Author details \\ ${ }^{1} J a p a n$ Agency for Marine-Earth Science and Technology, 3173-25 Showa-machi, Kanazawa-ku, Yokohama, Kanagawa 236-0001, Japan. ${ }^{2}$ Department of Environmental Sciences, Institute of Marine and Coastal Sciences, Rutgers University, 14 College Farm Rd, New Brunswick, NJ 08901-8551, USA. ${ }^{3}$ Ocean Sciences Department, University of California Santa Cruz, 1156 High Street, Santa Cruz, CA 95064, USA. ${ }^{4}$ University of Maryland Center for Environmental Science, Horn Point Laboratory, PO Box, 775, Cambridge, MD 21613, USA. ${ }^{5}$ College of Fisheries and Ocean Sciences, University of Alaska Fairbanks, 2150 Koyukuk Drive, Fairbanks, AK 99775-7220, USA.}

Received: 18 March 2018 Accepted: 7 January 2019

Published online: 29 January 2019

\section{References}

Barnes JT, MacCall AD, Jacobson LD, Wolf P (1992) Recent population trends and abundance estimates for the Pacific sardine (Sardinops-Sagax). Calif Coop Oceanic Fish Invest Rep 33:60-75

Beamish RJ, McFarlane GA, King JR (2000) Fisheries climatology: understanding decadal scale processes that naturally regulate British Columbia fish populations. In: Harrison PJ, Parsons TR (eds) Fisheries oceanography: an integrative approach to fisheries ecology and management. Blackwell Science, Oxford, pp 94-145

Benson AJ, Trites AW (2002) Ecological effects of regime shifts in the Bering Sea and eastern North Pacific Ocean. Fish Fish 3:95-113 
Butler JL, Smith PE, Lo NCH (1993) The effect of natural variability of life-history parameters on anchovy and sardine population growth. California Cooperative Oceanic Fisheries Investigations Reports 34:104-111

Carton JA, Chepurin G, Cao XH, Giese B (2000) A simple ocean data assimilation analysis of the global upper ocean 1950-95. Part I: methodology. J Phys Oceanogr 30:294-309

Cayan DR (1992) Latent and sensible heat-flux anomalies over the northern oceans - driving the sea-surface temperature. J Phys Oceanogr 22:859-881

Chavez FP, Ryan J, Lluch-Cota SE, Niquen M (2003) Sardine fishing in the early 20th century - response. Science 300:2033-2033

Collie JS, Botsford L, Hastings A, Kaplan IC, Largier JL, Livingston PA, Plagányi É, Rose KA, Wells BK, Werner FE (2016) Ecosystem models for fisheries management: finding the sweet spot. Fish Fish 17:101-125

Conkright ME, Boyer TP (2002) World Ocean Atlas 2001: Objective Analyses, Data Statistics, and Figures. CD-ROM Documentation, National Oceanographic Data Center, Silver Spring, MD

Cushing DH (1990) Plankton production and year-class strength in fish populations: an update of match/mismatch hypothesis. Adv Mar Biol 26:249-293

Deyle ER, Fogarty M, Hsieh CH, Kaufman L, MacCall AD, Munch SB, Perretti CT, Ye $H$, Sugihara G (2013) Predicting climate effects on Pacific sardine. Proc Natl Acad Sci 110(16):6430-6435

Fiechter J, Rose KA, Curchitser EN, Hedstrom KS (2015) The role of environmental controls in determining sardine and anchovy population cycles in the California current: analysis of an end-to-end model. Prog Oceanogr 138:381-398

Fielder PC (1984) Some effects of El Niño 1983 on the northern anchovy. Calif Coop Oceanic Fish Invest Rep 25:53-58

Garcia-Reyes M, Largier JL (2012) Seasonality of coastal upwelling off central and northern California: new insights, including temporal and spatial variability. J Geophys Res Oceans 117

Graham NE (1994) Decadal-scale climate variability in the tropical and North Pacific during the 1970s and 1980s: observations and model results. Clim Dyn 10:135-162

Haidvogel DB et al (2008) Ocean forecasting in terrain-following coordinates: formulation and skill assessment of the Regional Ocean Modeling System. J Comput Phys 227:3595-3624

Hare SR, Mantua NJ (2000) Empirical evidence for North Pacific regime shifts in 1977 and 1989. Prog Oceanogr 47:103-145

Hernandez-Vazquez S (1994) Distribution of eggs and larvae from sardine and anchovy off California and Baja California 1951-1989. Calif Coop Oceanic Fish Invest Rep 35:94-107

Hjort J (1914) Fluctuation in the great fisheries of northern Europe viewed in light on biological research. Rapports. Conceil Permanent International pour l'Exploration de la Mer

Houde ED (1987) Fish early life dynamics and recruitment variability. Am Fish Soc Symp 2:17-29

Humston R, Ault JS, Lutcavage M, Olson DB (2000) Schooling and migration of large pelagic fishes relative to environmental cues. Fish Oceanogr 9:136-146

Humston R, Olson DB, Ault JS (2004) Behavioral assumptions in models of fish movement and their influence on population dynamics. Trans Am Fish Soc 133:1304-1328

Hunter JR, Lo NCH, Leong RJH (1985) Batch fecundity in multiple spawning fishes. In: Lasker R (ed) An egg production method for estimating spawning biomass of pelagic fish: application to the northern anchovy, Engraulis mordax. NOAA technical report no. NMFS 36, pp 67-77

Husby DM, Nelson CS (1982) Turbulence and vertical stability in the California current. Calif Coop Oceanic Fish Invest Rep 23:113-129

Jacobson LD, Lo NCH, Barnes JT (1994) A biomass-based assessment model for northern anchovy, Engraulis-Mordax. Fish Bull 92:711-724

Jacobson LD, MacCall AD (1995) Stock recruitment models for Pacific sardine (Sardinops-Sagax). Can J Fish Aquat Sci 52:2062-2062

Jacox MG, Edwards (2011) Effect of stratification and shelf slope on nutrient supply in coastal upwelling regions. J Geophys Res 166:C03019

Jeronimo G, Gomez-Valdes J (2010) Mixed layer depth variability in the tropical boundary of the California current, 1997-2007. J Geophys Res 115:C05014

Kaplan IC, Koehn LE, Hodgson EE, Marshall KN, Essington TE (2017) Modeling food web effects of low sardine and anchovy abundance in the California current. Ecol Model 359:1-24

Kara AB, Rochford PA, Hurlburt HE (2000) An optimal definition for ocean mixed layer depth. J Geophys Res Oceans 105:16803-16821
Kawasaki T (1983) Why do some pelagic fish have wide fluctuations in their numbers? Biological basis from the viewpoint of evolutionary ecology. FAO Fish Rep 291:1065-1080

Kishi MJ et al (2007) NEMURO - a lower trophic level model for the North Pacific marine ecosystem. Ecol Model 202:12-25

Large WG, Yeager SG (2008) The global climatology of an interannually varying air-sea flux data set. Clim Dyn 33:341-363

Lindegren M, Checkley DM, Rouyer T, MacCall AD, Stenseth NC (2013) Climate, fishing, and fluctuations of sardine and anchovy in the California current. Proc Natl Acad Sci 110(33):13672-13677

Lluch-Belda D, Crawford RJM, Kawasaki T, MacCall AD, Parrish RH, Schwartzlose RA, Smith PE (1989) World-wide fluctuations of sardine and anchovy stocks: the regime problem. S Afr J Mar Sci 8:195-205

Lluch-Belda D, Schwartzlose RA, Serra R, Parrish R, Kawasaki T, Hedgecock D, Crawford RJM (1992) Sardine and anchovy regime fluctuations of abundance in four regions of the world oceans: a workshop report. Fish Oceanogr 1:339-347

Lo NCH, Smith PE, Butler JL (1995) Population growth of northern anchovy and Pacific sardine using stage-specific matrix models. Marine Ecology Progress Series 127:15-35

Mackas DL, Thomson RE, Galbraith M (2001) Changes in the zooplankton community of the British Columbia continental margin, 1985-1999, and their covariation with oceanographic conditions. Can J Fish Aquat Sci 58:685-702

McFarlane GA, Beamish RJ (1999) Sardines return to British Columbia waters. In Proceedings of the 1998 Science Board symposium on the impacts of the 1997/1998 El Nino event on the North Pacific Ocean and its Marginal Seas. PICES Science Report \#10 110pp.

McFarlane GA, King JR, Beamish RJ (2000) Have there been recent changes in climate? Ask the fish. Prog Oceanogr 47:147-169

McGowan JA, Bograd SJ, Lynn RJ, Miller AJ (2003) The biological response to the 1977 regime shift in the California current. Deep-Sea Res II Top Stud Oceanogr 50:2567-2582

Miller AJ, Dayan DR, Barnett TP, Graham NE, Oberhuber JM (1994) The 1976-77 climate shift of the Pacific Ocean. Oceanography 7:21-26

Moser HG, Charter RL, Smith PE, Ambrose DA, Watson W, Charter SR, Sandknop EM (2001) Distributional Atlas of Fish Larvae and Eggs in the Southern California Bight Region: 1951-1998. CalCOFI Atlas no.34 Southwest Fisheries Science Center, La Jolla, CA

Parnell PE, Miller EF, Lennert-Cody CE, Dayton PK, Carter ML, Stebbins TD (2010) The response of giant kelp (Macrocystis pyrifera) in southern California to lowfrequency climate forcing. Limnol Oceanogr 55:2686-2702

Pickett MH, Schwing FB (2006) Evaluating upwelling estimates off the west coasts of North and South America. Fish Oceanogr 15:256-269

Politikos DV, Curchitser EN, Rose KA, Checkley DM, Fiechter J (2018) Climate variability and sardine recruitment in the California current: a mechanistic analysis of an ecosystem model. Fish Oceanogr 27:602

Qiu B, Kelly KA (1993) Upper-ocean heat balance in the Kuroshio extension region. J Phys Oceanogr 23:2027-2041

Radovitch J (1979) Managing pelagic schooling prey species. In: Predator-Prey Systems in Fisheries Management. Sport Fishing Institute, Washington, D.C

Rodionov SN (2004) A sequential algorithm for testing climate regime shifts. Geophys Res Lett 31

Roemmich D (1992) Ocean warming and sea-level rise along the southwest US coast. Science 257:373-375

Rose KA et al (2015) Demonstration of a fully-coupled end-to-end model for small pelagic fish using sardine and anchovy in the California current. Prog Oceanogr 138:348-380

Rykaczewski RR, Checkley DM (2008) Influence of ocean winds on the pelagic ecosystem in upwelling regions. Proc Natl Acad Sci U S A 105:1965-1970

Ryther JH (1969) Photosynthesis and fish production in the sea. Science 166:72-76

Scheffer M, Baveco JM, Deangelis DL, Rose KA, Vannes EH (1995) Super-individuals a simple solution for modeling Large populations on an individual basis. Ecol Model 80:161-170

Schroeder ID, Santora JA, Moore AM, Edwards CA, Fiechter J, Hazen EL, Bograd SJ, Field JC, Wells BK (2014) Application of a data-assimilative regional ocean modeling system for assessing California Current System ocean conditions, krill, and juvenile rockfish interannual variability. Geophys Res Lett 41: 5942-5950

Schwartzlose RA et al (1999) Worldwide large-scale fluctuations of sardine and anchovy populations. S Afr J Mar Sci 21:289-347 
Shchepetkin AF, McWilliams JC (2005) The regional oceanic modeling system (ROMS): a split-explicit, free-surface, topography-following-coordinate oceanic model. Ocean Model 9:347-404

Smith RL (1968) Upwelling. Oceanography and marine biology. An Annual Review 6:11-46

Song H, Miller AJ, Cornuelle BD, Di Lorenzo E (2011) Changes in upwelling and its water sources in the California Current System driven by different wind forcing. Dyn Atmos Oceans 52:170-191

Stone G, Goebel J, Webster S (1997) Pinniped Populations, Eastern North Pacific Status, Trends and issues, A symposium of the127th annual meeting of the American fisheries society. New England aquarium, Conservation Department, Central Warf, Boston

Traganza ED, Redalje DG, Garwood RW (1987) Chemical flux, mixed layer entrainment, and phytoplankton blooms at upwelling fronts in the California coastal zone. Cont Shelf Res 7:89-105

Van der Lingen CD, Hutchings L, Field JG (2006) Comparative trophodynamics of anchovy Engraulis encrasicolus and sardine Sardinops sagax in the southern Benguela: are species alternations between small pelagic fish trophodynamically mediated? Afr J Mar Sci 28:465-477

Venrick EL, Mcgowan JA, Cayan DR, Hayward TL (1987) Climate and chlorophyll-a - long-term trends in the central North Pacific-Ocean. Science 238:70-72

Watkins KS, Rose KA (2013) Evaluating the performance of individual-based animal movement models in novel environments. Ecol Model 250:214-234

Yatsu A, Aydin KY, King JR, McFarlane GA, Chiba S, Tadokoro K, Kaeriyama M, Watanabe $Y$ (2008) Elucidating dynamic responses of North Pacific fish populations to climatic forcing: influence of life-history strategy. Prog Oceanogr 77:252-268

\section{Submit your manuscript to a SpringerOpen ${ }^{\circ}$ journal and benefit from:}

- Convenient online submission

- Rigorous peer review

- Open access: articles freely available online

- High visibility within the field

- Retaining the copyright to your article

Submit your next manuscript at $\boldsymbol{\nabla}$ springeropen.com 